\title{
Structural control and system-level behavior of the seismic cycle at the Nankai Trough
}

\author{
Qibin Shi ${ }^{1}$, Sylvain Barbot ${ }^{2 *}$ (D, Shengji Wei ${ }^{1}$, Paul Tapponnier ${ }^{3}$, Takanori Matsuzawa ${ }^{4}$ and Bunichiro Shibazaki ${ }^{5}$
}

\begin{abstract}
The Nankai Trough in Southwest Japan exhibits a wide spectrum of fault slip, with long-term and short-term slowslip events, slow and fast earthquakes, all associated with different segments down the plate interface. Frictional and viscous properties vary depending on rock type, temperature, and pressure. However, what controls the downdip segmentation of the Nankai subduction zone megathrust and how the different domains of the subduction zone interact during the seismic cycle remains unclear. Here, we model a representative cross-section of the Nankai subduction zone offshore Shikoku Island where the frictional behavior is dictated by the structure and composition of the overriding plate. The intersections of the megathrust with the accretionary prism, arc crust, metamorphic belt, and upper mantle down to the asthenosphere constitute important domain boundaries that shape the characteristics of the seismic cycle. The mechanical interactions between neighboring fault segments and the impact from the long-term viscoelastic flow strongly modulate the recurrence pattern of earthquakes and slow-slip events. Afterslip penetrates down-dip and up-dip into slow-slip regions, leading to accelerated slow-slip cycles at depth and longlasting creep waves in the accretionary prism. The trench-ward migrating locking boundary near the bottom of the seismogenic zone progressively increases the size of long-term slow-slip events during the interseismic period. Fault dynamics is complex and potentially tsunami-genic in the accretionary region due to low friction, off-fault deformation, and coupling with the seismogenic zone.
\end{abstract}

Keywords: Friction, Rheology, Subduction zones

\section{Introduction}

Subduction megathrusts accumulate and release mechanical energy through a variety of slip modes, including earthquakes, low-frequency earthquakes, slow-slip events, and stable creep. These different types of events can be discriminated in seismo-geodetic observations by their distinct peak slip velocities, frequency spectra, durations, and recurrence intervals (e.g., Wallace and Beavan 2006; Ito et al. 2007; Araki 2017). Slow earthquakes involve slip velocities and rupture speeds fast enough to be detected by broadband seismometers, but not fast enough to generate high-frequency seismic waves (Barbot 2019b). Slow-slip events are too slow to

\footnotetext{
*Correspondence: sbarbot@usc.edu

${ }^{2}$ Department of Earth Sciences, University of Southern California, Los Angeles, USA

Full list of author information is available at the end of the article
}

be detected by seismometers due to their low frequency content, but may be monitored with geodetic instruments. Hence, in this paper, we refer to slow earthquakes as any of low-frequency earthquakes, very-low-frequency earthquakes and non-volcanic tremors, but exclude slowslip events from this denomination. In contrast, we refer to slow-slip event as either long-term or short-term slowslip events. At subduction zones, each slip mode is commonly associated with distinct down-dip segments of the megathrust (Oleskevich et al. 1999; Rogers and Dragert 2003; Peng and Gomberg 2010; Hirose and Obara 2005; Obara and Kato 2016; Gao and Wang 2017). Structural control also operates along strike in various ways (e.g., Kodaira et al. 2006; Sieh 2008; Contreras-Reyes et al. 2010; Contreras-Reyes and Carrizo 2011; Moreno 2012; Lin 2013; Metois et al. 2016; Bassett et al. 2016; Nocquet 2017; Philibosian 2017; Vaca et al. 2018; Van Rijsingen 
et al. 2018; Nishikawa et al. 2019), but the down-dip segmentation of slip behavior seems to be an ubiquitous feature of subduction megathrusts. The Nankai Trough offers a striking example of down-dip segmentation, with shallow low-frequency and very-low-frequency earthquakes, large megathrust earthquakes, long-term and short-term slow-slip events, the latter accompanied with deep low-frequency tremors (Fig. 1).

This study represents an attempt to reconcile geological and seismo-geodetic observations at the Nankai Trough, including insights from other subduction zones. We first review the general characteristics of subduction megathrusts, in particular, the seismic potential and source characteristics at each structural segment. The shallowest fault segment, overlain by the accretionary prism, was once thought to undergo stable sliding due to the low seismicity near the trench late in the seismic cycle and the presence of poorly consolidated sediments. However, accretionary prisms are known to host tsunami earthquakes (Kanamori 1972; Pelayo and Wiens 1992; Satake and Tanioka 1999; Bilek and Lay 2002; Geersen 2019), for example, along the Sunda arc (Ammon et al. 2006; Kanamori et al. 2010; Lay et al. 2011; Newman et al. 2011; Bilek et al. 2011; Satake et al. 2013), the Hikurangi subduction zone (Bell et al. 2014), Nicaragua (Kanamori and Kikuchi 1993; Satake 1994), the Aleutian Islands (Johnson and Satake 1997), the Peru-Chile trench (Pelayo and Wiens 1990), and the Kuril-Kamchatka trench (Kanamori 1972). The rupture of giant earthquakes also propagates to the trench, for example, the $1960 \mathrm{Val}-$ divia, Chile, the 1964 Alaska, the 2004 Aceh-Andaman, the 2010 Maule, Chile, and the 2011 Tohoku-Oki, Japan

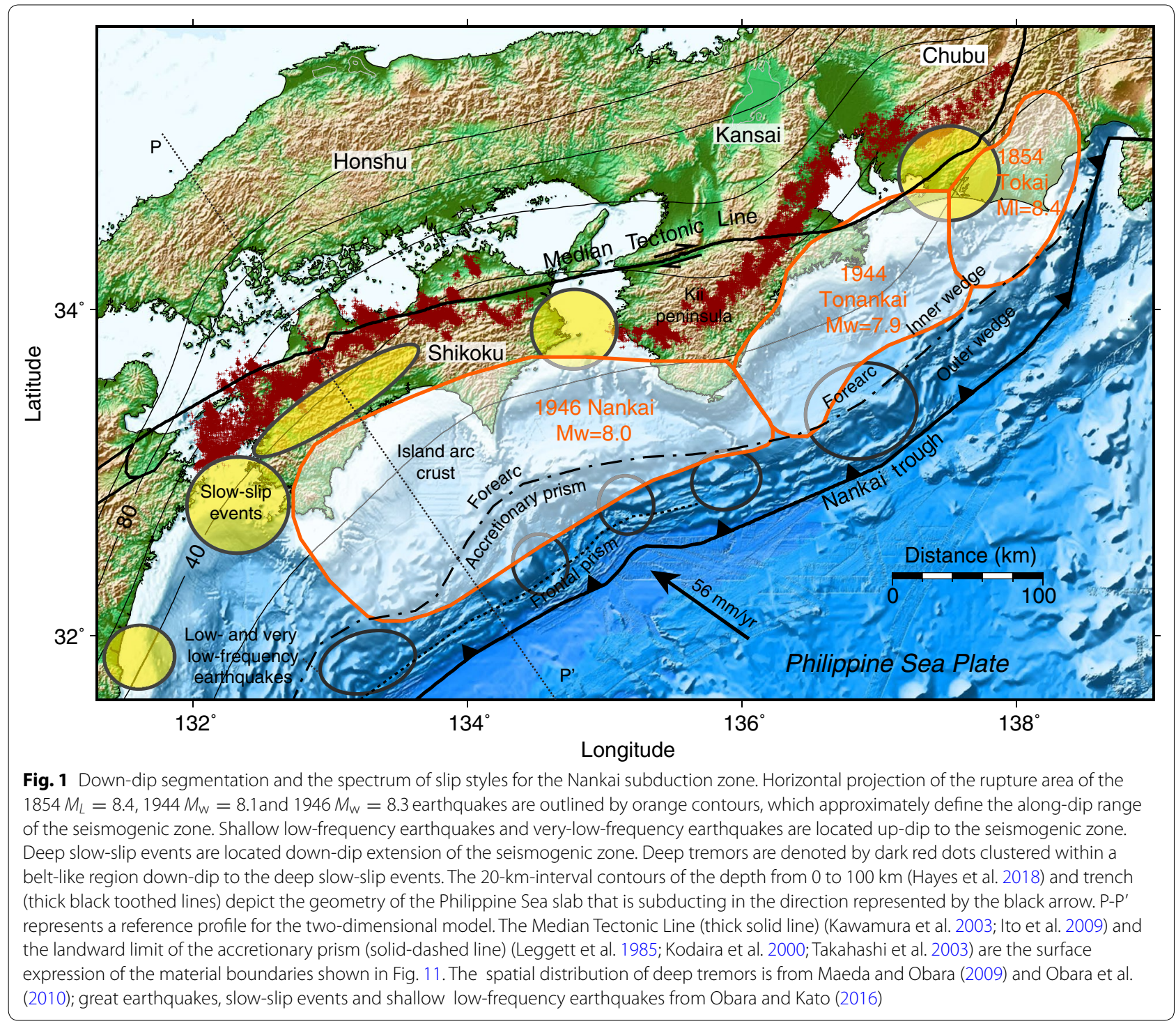


earthquakes (Plafker 1965; Ishii et al. 2005; Lorenzo-Martín et al. 2006; Yue et al. 2014; Tomita et al. 2017), with the notable exception of the 2005 Nias, Sumatra earthquake (Hsu et al. 2006; Konca et al. 2007). Several mechanisms have been proposed to explain the failure of the shallow megathrust in giant ruptures. Noda and Lapusta (2010) use thermal pressurization to facilitate dynamic weakening in a creeping segment. Kozdon and Dunham (2013) invoke wave-mediated propagation of rupture into a shallow velocity-strengthening segment. In these models, seismic ruptures nucleate in the seismogenic zone and propagate up-dip to the velocity-strengthening segment. However, discoveries of low-frequency earthquakes and tectonic tremors within the shallow fault segment underlying the accretionary prism, such as in the Nankai Trough (Sugioka 2012; Yamashita 2015; Toh et al. 2018; Nakano et al. 2018), Costa Rica (Jiang et al. 2012; Dixon et al. 2014) and New Zealand (Wallace and Beavan 2006; Wallace 2016; Wallace et al. 2017), indicate that slip instabilities can nucleate at shallow depth. Laboratory experiments on clay minerals indicate a low static friction of accretionary sediments and a complex temperature and velocity dependence of dynamic friction (Saffer and Marone 2003; Ikari 2019) that includes velocity-weakening behavior at tectonic loading rates (Ikari and Kopf 2017).

The seismogenic zone is a major section of the megathrust overlain by the continental crust or arc crust, depending on the tectonic setting, that generates large earthquakes (e.g., Pacheco et al. 1993; Heuret et al. 2011; Hayes et al. 2012). The down-dip limit of the seismogenic zone is thought to coincide with the upper-plate Moho or a shallower isotherm. The frictional properties of quartzrich crystalline rocks explain the firmly velocity-weakening properties of this region (Scholz et al. 1972; Tullis and Weeks 1986; Kilgore et al. 1993; Blanpied et al. 1991, 1995; Mitchell et al. 2013). The low-angle intersection of the megathrust with the upper-plate crust at subduction zones forms the source region for Earth's largest earthquakes. The oblique convergence at the trench is often accommodated by strike-slip faulting in the forearc, for example, the Median Tectonic Line in Southwest Japan, the Sumatran Fault in Indonesia, the Linquine-Ofqui fault system in South Chile, and the Fairweather and Denali faults in Alaska (Schellart and Rawlinson 2013). Earthquake source properties vary among subduction zones (e.g., Ye et al. 2016; Hayes 2017; Meier et al. 2017; Ye et al. 2018), but a remaining puzzling behavior is the full and partial ruptures of the seismogenic zone in supercycles. For example, coral, turbidite, and paleo-tsunami records indicate a wide range of earthquake sizes in the Sunda trench (Sieh 2008; Patton 2015; Philibosian 2017; Rubin et al. 2017). In the Japan trench, only earthquakes of moment magnitude 7 preceded the 2011 Tohoku megaquake in the last century (Yamanaka and Kikuchi 2004; Nakata et al. 2016). Partial rupture of the seismogenic zone also occurs in a continental collision setting, for example, along the Main Himalayan front (Sapkota et al. 2013; Bollinger et al. 2013; Bilham 2015; Mencin 2016; Hubbard et al. 2016; Feng 2017). Herrendörfer et al. (2015), Michel et al. (2017), and Barbot (2019b) argue that the super-cycle is a self-emergent behavior from the nonlinear dynamics of fault slip favored by wide seismogenic zones. Qiu et al. (2016) and Hubbard et al. (2016) suggest the important role of morphological gradients, i.e., local changes in the geometry of the plate interface. How the earthquake recurrence and super-cycle patterns are affected by surrounding activity, notably slow-slip events and asthenospheric viscoelastic flow is another important unknown.

At most subduction zones, the seismogenic zone is followed down-dip by a stability transition where the megathrust slips in slow, dominantly aseismic episodes (e.g., Rogers and Dragert 2003; Schwartz and Rokosky 2007; Szeliga et al. 2008; Gomberg and Group 2010; Beroza and Ide 2011; Kobayashi 2014; Obara and Kato 2016; Gao and Wang 2017; Bürgmann 2018). Slow-slip events are thought to occur in a narrow metamorphic belt of serpentinized rocks where the development of frictional instabilities is inhibited by high temperature and high pore-fluid pressure (Kodaira et al. 2004; Katayama et al. 2013; Audet and Bürgmann 2014; Frank et al. 2015; Goswami and Barbot 2018; Audet and Schaeffer 2018; Nakajima and Uchida 2018; Cruz-Atienza et al. 2018). The long-term slow-slip events, characterized by durations of months or years and recurrence time of several years (Kobayashi 2014), take place immediately underneath the seismogenic zone, in the mantle wedge corner, representing either slip on the megathrust or distributed flow in a narrow metamorphic shear zone (Platt et al. 2018). In contrast, the short-term slow-slip events, with durations of days or weeks and recurrence times of several months (Hirose and Obara 2005, 2006; Obara et al. 2004), take place in the upper mantle and are accompanied by substantial tremors and low-frequency earthquakes (Obara 2002; Obara et al. 2004; Shelly et al. 2006; Ito et al. 2007), a phenomenon referred to as episodic tremor and slip. Examples include the Cascadia (Rogers and Dragert 2003) and Nankai (Obara and Kato 2016) subduction zones (Fig. 1). The slow-slip phenomenon can be reproduced in a laboratory setting within the stable-weakening conditions promoted by low normal stress (Leeman et al. 2016; Scuderi et al. 2017; Mclaskey and Yamashita 2017; Ikari 2019). Conditional stability, a situation that occurs when the size of nucleation is commensurate with the size of the fault segment, can be 
invoked to simulate slow-slip events (e.g., Liu and Rice 2005; Rubin 2008; Li and Liu 2016, 2017). Conditional stability occurs over a wide range of parameters, especially considering near velocity-neutral conditions, where most of the available energy is consumed by fracture (Wu and Chen 2014; Barbot 2019b). Furthermore, stability can be promoted by activation of viscoelastic flow in a semi-brittle matrix (Goswami and Barbot 2018), velocitydependent frictional properties (Shibazaki and Shimamoto 2007; Matsuzawa et al. 2010; Shibazaki et al. 2011) or dilatancy effects (Liu and Rubin 2010; Segall et al. 2010; Segall and Bradley 2012). The down-dip limit of slowslip is an isotherm corresponding to the stable creep of olivine and pyroxene. Below this depth, the plate interface is stable, creeping at the plate rate, only modulated by stress perturbations from earthquakes and slow-slip events (Barbot 2018b). As the recurrence times of slowslip events and large earthquakes are so widely different, the mechanical coupling between the seismogenic zone and the slow-slip region is poorly known. However, slowslip events can be triggered by distant earthquakes (Araki 2017; Wallace et al. 2017; Wei et al. 2018), act like structural barriers (Vaca et al. 2018; Rolandone 2018), or trigger other slow-slip events (Payero et al. 2008; Kano et al. 2019). Along-strike segmentation of slow-slip events in the Nankai Trough follows the spatial pattern of coupling in the seismogenic zone (Takagi et al. 2019). Numerical simulations indicate that the recurrence pattern of slow slip is modulated by the earthquake cycle (Matsuzawa et al. 2010).

The subduction of an oceanic slab below another plate is resisted by frictional drag along the megathrust that results in extremely localized brittle deformation. Consequently, the two plates are separated by the megathrust at geological time scales from the trench down to a depth of about $80 \mathrm{~km}$ (Wada and Wang 2009), which also marks the down-dip limit of stable creep, the brittle-ductile transition, and the termination of the megathrust. Below this depth, the subducting slab is permanently coupled with the upper mantle rocks, entraining a convection cell that drives local circulation of volatiles, culminating in the formation of a volcanic arc at most subduction zones (e.g., Spiegelman and McKenzie 1987; Kawakatsu and Watada 2007; van Keken et al. 2011). The termination of frictional heating associated with megathrust slip seems required to explain the pattern of surface heat flow at most subduction zones (Wada and Wang 2009). As a result, $50 \%$ of all frontal arc volcanoes lie between 85 and $119 \mathrm{~km}$ above the subducting slab (Syracuse and Abers 2006). The volatiles originate from the hydrous metamorphism of upper mantle rocks at the spreading center and from bend-related faulting at the outer rise (e.g., Ranero et al. 2003; Rüpke et al. 2004; Naif et al. 2013, 2015). The
Nankai Trough offshore Honshu is a notable exception, not being associated with a volcanic arc, presumably due to the shallow dip angle of the Philippine Sea slab that inhibits efficient corner flow (Nakajima and Hasegawa 2007; Hirose et al. 2008; Hayes et al. 2018) and the influence of the Shikoku back-arc basin behind the Izu arc. The deformation of the mantle wedge above the slab is accommodated by the viscoelastic flow of peridotite, facilitated by the weakness of olivine at this temperature and pressure (Karato et al. 1986; Mei and Kohlstedt 2000; Van der Wal et al. 1993; Chopra 1997; Karato and Jung 2003; Masuti et al. 2019). Thermally activated viscoelastic flow in the asthenosphere facilitates plate tectonics and the Wilson cycle (e.g., Burke 2011). Asthenospheric flow is modulated by the seismic cycle (Barbot 2018b), creating large-scale deformation during the postseismic period (Savage and Prescott 1978; Hirahara 2002; Hu et al. 2004; Wang 2007; Pollitz et al. 2008; Wang et al. 2012; Sun 2014; Masuti et al. 2016; Klein et al. 2016; Li et al. 2018; Qiu et al. 2018; Weiss et al. 2019). Viscoelastic flow and fault slip are mechanically coupled during postseismic deformation (Agata et al. 2019; Muto et al. 2011). However, the impact of viscoelastic flow on the recurrence pattern of earthquakes and slow-slip events is poorly known.

Schematics of heat, mass, and fluid transport at subduction zones abound (e.g., Hyndman et al. 1997; Stern 2002; Agard et al. 2009, and references therein). However, how lithology, temperature, and structure affects the seismic cycle is not firmly established. Scholz (1998) invokes the temperature dependence of the friction properties of granite to define the boundary of the seismogenic zone. Lay et al. (2012) describe how other segments can be associated with tsunami earthquakes and short-period seismic radiations. Gao and Wang (2017) highlight the rheological separation of the megathrust into regions of different rupture styles. But the first-order, structural control on the dynamics of fault slip has not been properly asserted. Here, we describe a model of the seismic cycle at the Nankai subduction zone where the style of fault dynamics is controlled by the structure and composition of the overriding plate. The intersection of the megathrust with thoroughly different terranes creates structural domain boundaries that profoundly affect the style of rupture. Using the Nankai Trough as a backdrop because of the manifestation of many rupture styles, we describe how each region of the megathrust-the accretionary prism, arc crust, metamorphic belt, mantle lid, and upper mantle-can be associated with characteristic physical properties and dimensions that have a long-lasting influence on the unfolding of the seismic cycle. We highlight how the nonlinear dynamics of fault slip and the interplay between each domain introduces additional 
complexity, such as full and partial earthquake ruptures, modulation of slow-slip during the seismic cycle, and aperiodic super-cycles, that overprint the structural control. We also discuss the mechanical coupling between the brittle domain and the viscoelastic substrate.

The manuscript is organized as follows. In the following section, we propose a structural model of the megathrust at the Nankai Trough along a representative cross-section. We describe a numerical model that reproduces the salient features over the following sections. In the third section, we introduce the constitutive laws for fault slip and viscoelastic flow and the relevant governing equations. In the fourth section, we discuss the physical and structural properties of the model. In the fifth section, we present numerical simulations of the systemlevel dynamics. In the following sections, we focus on the mechanical coupling between earthquakes and the shortterm and long-term slow-slip events. We also discuss the impact of viscoelastic flow in the oceanic asthenosphere and the mantle wedge on the recurrence pattern of earthquakes. This is followed by a discussion and conclusion.

\section{Structural and lithological control on megathrust dynamics}

We describe a representative cross-section of the Nankai Trough where the major rupture styles are associated with structural boundaries of the overriding plate. From the trench to the asthenosphere, we describe five megathrust segments delineated by structural boundaries or an isotherm (Fig. 2). Each of these segments is associated with physical characteristics and a length scale that control fault dynamics at first order. We do not resolve the interactions with the Median Tectonic Line because pure strike-slip and thrust faults are mechanically decoupled in two-dimensional approximations.

Segment A. The top segment represents the intersection of the megathrust with the accretionary prism, a sedimentary sink characterized by intense off-fault deformation (Moore et al. 1990; Hubbard et al. 2015; Sathiakumar et al. 2020), low rigidity (Sallarès and Ranero 2019), and particularly low static friction (e.g., Byrne and Fisher 1990; Cubas et al. 2013). The shortening taken up by secondary faults and folds in the upper plate builds topography and reduces the long-term loading rate on the megathrust, resulting in a low rate of seismicity on the plate interface. The low static friction coefficient of clay minerals and derived sedimentary rocks greatly affects the rupture style, resulting in anomalously long, complex ruptures (Barbot 2019b). The many high-angle ramps and splay faults of the frontal prism are responsible for the tsunami-genic potential. The dominantly velocity-weakening properties of the plate interface at these depths (Saffer and Marone 2003; Ikari and Kopf
2017; Ikari 2019) allows for the development of slowslip events, slow earthquakes, and tsunami earthquakes. Deep ruptures may also propagate through the accretionary prism and arrest near the trench.

Segment B. The seismogenic zone corresponds to the cold section of the low-angle intersection between the megathrust and the arc crust. The rupture of the seismogenic zone is controlled by the frictional properties of quartz-rich crystalline rocks, which are considered velocity-weakening at temperatures up to at least $350{ }^{\circ} \mathrm{C}$ (Blanpied et al. 1991, 1995; Mitchell et al. 2013, 2016). The large intersection of the megathrust down to this isotherm allows great and giant interplate ruptures. The width of the seismogenic zone provides a characteristic length scale for rupture size, but full and partial ruptures of the seismogenic zone take place spontaneously because of the nonlinear dynamics of the system (Kato 2012; Wu and Chen 2014; Michel et al. 2017; Cattania and Segall 2018; Barbot 2019b; Cattania 2019). Giant earthquakes may also occur if ruptures propagate across segment boundaries.

Segment C. We associate the long-term slow-slip events with a metamorphic belt within the mantle wedge corner, a narrow serpentinized shear zone below the arc crust. The slow-slip events develop in antigorite-rich serpentinite, which is velocitystrengthening at the low temperatures and pressures of the seismogenic zone, but velocity-weakening at and above $450{ }^{\circ} \mathrm{C}$ (Okazaki et al. 2013; Katayama et al. 2013; Okazaki and Katayama 2015). The low activation energy of the viscoelastic flow of serpentinite (Hilairet et al. 2007) may hinder the development of frictional instabilities in this region (Goswami and Barbot 2018). The depth of the metamorphic belt coincides roughly with the arc lower crust farther inland, but the shear zone of the mantle wedge corner and the lower crust differ in composition.

Segment D. The episodic tremor and slip phenomenon coincides with the mantle lid, i.e., the brittle layer of the upper mantle, where olivine-rich peridotite exhibits velocity-weakening frictional properties at temperatures up to $600-800{ }^{\circ} \mathrm{C}$ (Boettcher et al. 207; King and Marone 2012). The proximity to the stability transition induced by high temperature creates the conditions for chaotic short-term slow slip where a macroscopic slow rupture is accompanied by intermittent slow earthquakes (Viesca 2016a, b; Barbot 2019b). The mix-mode failure with coincident slow and fast rupture during the same event may provide a first-order explanation for the intense tremor activity of this section.

Segment E. The deep velocity-strengthening segment of the megathrust corresponds to temperatures between that of the stability transition of peridotite 

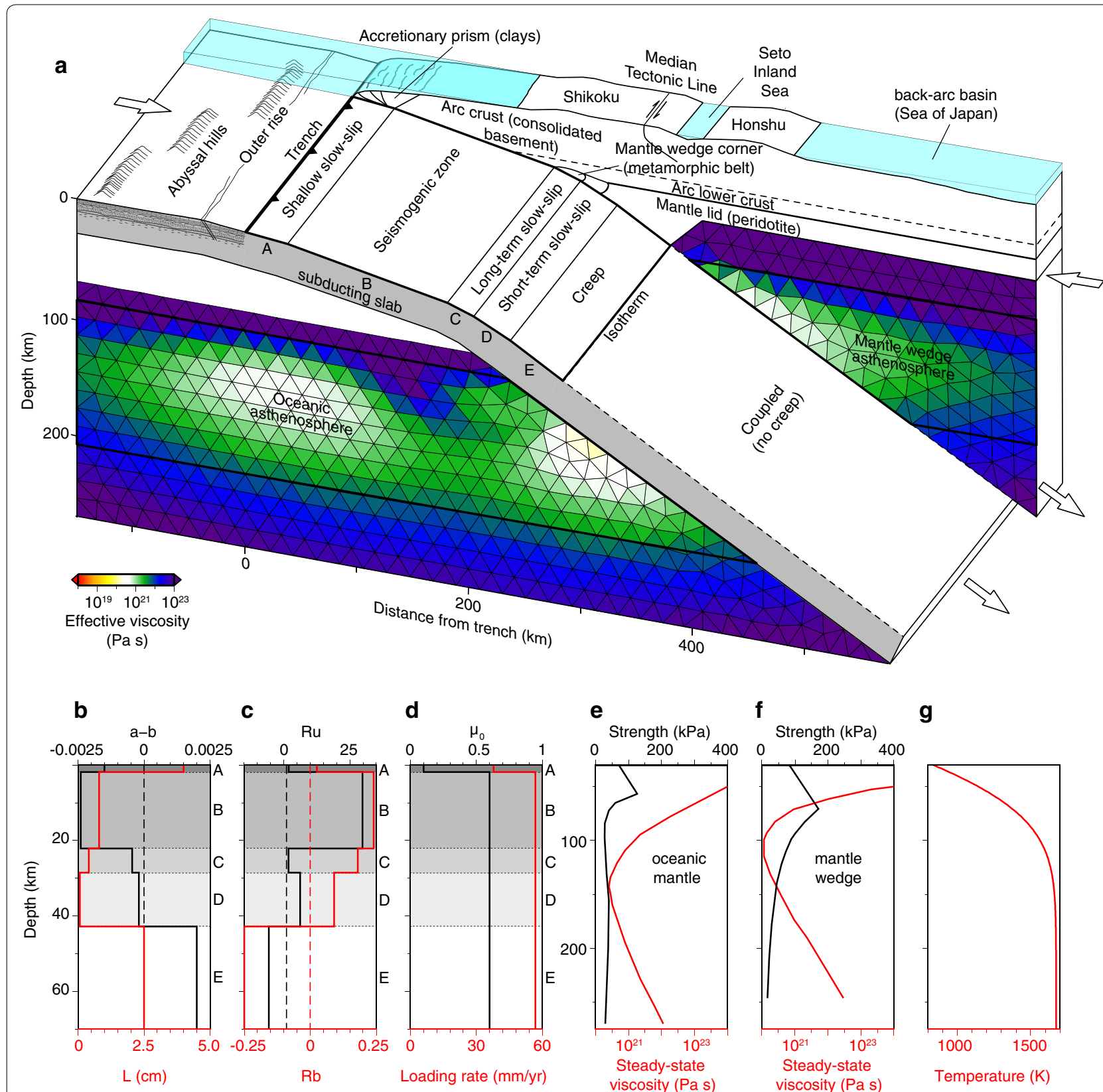

g

Fig. 2 Conceptual model and physical parameters for the down-dip segmentation of the megathrust and the ductile substrate. a Synoptic look at the relationship between brittle and ductile processes with a subduction zone geometry. The megathrust is segmented into the accretionary prism (segment A), seismogenic zone (segment B), metamorphic belt (segment C), mantle lid (segment D), and mantle wedge (segment E). The friction properties of these regions are controlled by the thermo-mechanical properties at the plate interface. The brittle-ductile transition occurs seaward of the volcanic arc. Corner flow in the mantle wedge starts landward of this boundary, in the mantle wedge asthenosphere. b Friction parameters $a-b$ and $L$ of segments $A$ to $E$, and $\mathbf{c}$ corresponding $R_{u}$ and $R_{b}$ numbers. $\mathbf{d}$ Static friction coefficient and loading rate along the megathrust. $\mathbf{e}$ Rheological parameters of the oceanic asthenosphere at steady state. $\mathbf{f}$ Rheological parameters of the mantle wedge at steady state. $\mathbf{g}$ Thermal gradient in the upper mantle

$\left(600-800{ }^{\circ} \mathrm{C}\right)$ and that of the brittle-ductile transition $\left(1000^{\circ} \mathrm{C}\right.$ or $80 \mathrm{~km}$ depth). Beyond this depth, the downgoing slab is bound to the mantle wedge rocks and fault slip is prevented or greatly limited. This segment plays an important role during postseismic relaxation, releasing the coseismic stress change rapidly with afterslip, and during the interseismic period towards loading of the seismogenic zone. 
In the following sections, we describe a two-dimensional model that implements this idealized structural segmentation of the megathrust. Compatible with previous findings, we show that megathrust dynamics is greatly controlled by the structure and composition of the upper plate, but that additional complexity and non-periodic recurrence patterns result from the nonlinear dynamics of the system. This results in a complex history of earthquakes and slow-slip events with large-scale and long-period characteristics that are predetermined by the structural layout.

\section{Constitutive laws and governing equations}

In this section, we describe the assumed constitutive relationships for fault friction and viscoelastic flow. We describe a modeling framework that allows us to simulate the dynamics of fault slip in a viscoelastic medium that includes the mechanical coupling between brittle and ductile deformation during the seismic cycle. We then discuss important take-aways from a dimensional analysis of the governing equations that allows us to discuss the emergence of a wide spectrum of rupture styles. These considerations provide the building blocks for simulating the short-term dynamics of subduction zones during the seismic cycle.

\section{Constitutive framework for fault slip}

The evolution of fault friction on a fault during all stages of the seismic cycle can be captured by the constitutive framework of rate-and-state friction introduced by Dieterich (1979), Ruina (1983), and Rice and Ruina (1983). The constitutive law is motivated by a wealth of laboratory experiments (Dieterich 1978; Marone et al. 1990; Marone and Kilgore 1993; Nakatani 2001; Yamashita et al. 2014; Lyu et al. 2019, and references therein) and is supported by various micro-physical models for the evolution of strength in fault gouge or bare contacts (Chester 1989; Sleep and Blanpied 1992; Sleep 1995, 2006; Barbot 2019a). The framework of rate-and-state friction has been useful to model a wide spectrum of rupture styles, including slow and fast ruptures (Rice and Tse 1986; Lapusta and Rice 2003; Hori et al. 2004; Liu and Rice 2005; Rubin 2008; Chen and Lapusta 2009; Kaneko et al. 2010; Barbot et al. 2012; Wei et al. 2015; Veedu and Barbot 2016; Lambert and Barbot 2016; Lui and Lapusta 2016; Salman et al. 2017; Yu et al. 2018; Ong et al. 2019) and the dynamics of quasi-static deformation in dominantly aseismic periods (Perfettini and Avouac 2004, 1992; Barbot et al. 2004; Bruhat et al. 2011; Rousset et al. 2012; Rollins et al. 2015).

Several forms of constitutive equations that fall into the rate-and-state framework have been proposed (Ruina
1983; Linker and Dieterich 1992; Rice and Ben-Zion 1996; Kato and Tullis 2001; Bizzarri 2011; Nagata et al. 2012), in particular due to uncertainties about the evolution law for the state variable and issues regarding regularization for vanishing velocities. In this study, we adopt the formulation proposed by Barbot (2019a), where the velocity across the fault zone is controlled by the area of the contact junctions that support the shear and normal loads. The model assumes the following constitutive relationship

$$
V=V_{0}\left(\frac{\tau}{\mathcal{A} \chi}\right)^{\frac{\mu_{0}}{a}} \exp \left[-\frac{Q}{R}\left(\frac{1}{T}-\frac{1}{T_{0}}\right)\right],
$$

where $V$ is the sliding velocity, $\tau$ is the norm of the shear traction resolved on the fault plane, $T$ is the local absolute temperature, $\mu_{0}$ is the static coefficient of friction at velocity $V_{0}$ and temperature $T_{0}, \mathcal{A}$ is the real area of contact divided by the nominal surface area, $\chi$ is the indentation hardness of the fault material, and $a \ll 1$ is a power exponent. Fault slip is thermally activated with the activation energy $Q ; R$ is the universal gas constant. The real area of contact depends primarily on the applied normal stress, but it evolves during the seismic cycle, modulated by changes in the morphology of the micro-asperities. Flattening of the micro-asperities increases the area of contact junctions and strengthens the fault. Comminution during fault slip reduces the average contact area and weakens the fault. This behavior is captured by a dependence on effective normal stress and a state variable

$$
\mathcal{A}=\frac{\mu_{0} \bar{\sigma}}{\chi}\left(\frac{\theta V_{0}}{L}\right)^{\frac{b}{\mu_{0}}}
$$

where $\bar{\sigma}$ is the effective normal stress, $L$ is the characteristic weakening distance, $b \ll 1$ is a power exponent, and $\theta$ is a state variable that represents the age of the contact, or equivalently, the duration of contact flattening (Barbot 2019a). Combining (1) and (2), we obtain the constitutive relationship

$$
V=V_{0}\left(\frac{\tau}{\mu_{0} \bar{\sigma}}\right)^{\frac{\mu_{0}}{a}}\left(\frac{\theta V_{0}}{L}\right)^{-\frac{b}{a}} \exp \left[-\frac{Q}{R}\left(\frac{1}{T}-\frac{1}{T_{0}}\right)\right] .
$$

To capture the evolution of the topography of the fault surface at the micro-scale, the state variable follows the evolution law (Barbot 2019a)

$$
\dot{\theta}=\exp \left[-\frac{H}{R}\left(\frac{1}{T}-\frac{1}{T_{0}}\right)\right]-\frac{V \theta}{L},
$$

where $H$ is the activation enthalpy for contact healing (Chester and Higgs 1992; Chester 1994). In this study, we assume isothermal conditions, and, in the limit of 
this approximation, Eqs. (3) and (4) represent a complete constitutive framework for the dynamics of fault slip. Choosing $T=T_{0}$, Eq. (4) simplifies to the aging law proposed by Ruina (1983). The parameters $a, b$, and $L$ have the same function as in the classical formulation of Ruina (1983), despite the multiplicative form of Eq. (3). The spatial distribution of the constitutive parameters $\mu_{0}, a, b$, and $L$ and the effective normal stress $\bar{\sigma}$ along the megathrust as a function of lithology and temperature will shape the dynamics of the seismic cycle.

The constitutive law of Eq. (3) takes a multiplicative form, differing in that regard from the additive, logarithmic form used elsewhere (e.g., Ruina 1983, and references therein). A truncated power series expansion of the multiplicative form, which remains valid for a wide range of velocities around $V_{0}=1 \mu \mathrm{m} / \mathrm{s}$, reduces to the additive form (Barbot 2019a). However, the logarithmic form is ill-posed for vanishing velocity and requires regularization, such as the one with a hyperbolic sine motivated by thermo-dynamic considerations proposed by Rice and Ben-Zion (1996). In contrast, the multiplicative form is valid for vanishing velocities and does not require additional regularization. The multiplicative form of rate-andstate friction described above produces a different style of rupture dynamics in weak faults $\left(\mu_{0} \leq 0.1\right)$, resulting in exceedingly long, multi-pulsed ruptures resembling that of tsunami earthquakes (Barbot 2019a, b).

\section{Constitutive framework for viscoelastic flow}

The deformation of crust and mantle rocks, inferred from laboratory experiments on aggregates or single crystals, is accommodated by several micro-mechanisms that include diffusion creep, dislocation creep, and dislocation glide (Karato et al. 1986; Hirth and Tullis 1992; Gleason and Tullis 1995; Chopra 1997; Mei and Kohlstedt 2000; Rybacki and Dresen 2000; Karato and Jung 2003; Hirth and Kohlstedt 2003; Dimanov and Dresen 2005). During steady-state, i.e., at constant stress or strain-rate, a constitutive relationship of the form

$$
\dot{\epsilon}=A \sigma^{n}\left(C_{\mathrm{OH}}\right)^{r} d^{-m} \exp \left(-\frac{E+p \Omega}{R T}\right)
$$

where $A$ is a constant pre-factor, $\sigma$ is the norm of the deviatoric stress, and $m, n$, and $r$ are power exponents, predicts the deformation-rate $\dot{\epsilon}$ based on in situ physical conditions, including water content $C_{\mathrm{OH}}$, grain-size $d$, pressure $p$, activation volume $\Omega$, activation energy $E$, and temperature $T$. For diffusion creep and pressuresolution creep, the power exponent is $n=1$, corresponding to linear viscoelasticity. For dislocation creep, $n>1$ and $m=0$, corresponding to a power-law rheology.
Dislocation glide has a nonlinear response with $n \sim 2$, but is also sensitive to grain-size $(m \neq 0)$ (Karato 2008).

During periods of rapid change of stress or strain-rate, other deformation processes take place within the rock or mineral structure, leading to a short phase of hardening that transitions to the steady-state response, usually referred to as transient creep (Chopra 1997; Wu et al. 2016). In contrast to steady-state, the micro-mechanics of transient creep are poorly understood and different constitutive relationships have been proposed (Sherburn et al. 2011; Thieme et al. 2018; Holtzman et al. 2018), but plastic anisotropy within single crystals may be an important factor (Masuti et al. 2019). Because of the rapid change imposed by the seismic cycle, transient creep may be operating during postseismic relaxation (Pollitz et al. 2008; Freed et al. 2010; Hoechner et al. 2011; Tang et al. 2019; Muto et al. 2011). The strain-rate of transient creep may be represented by an additional strain component (Masuti et al. 2016)

$$
\dot{\epsilon}_{\mathrm{K}}=A_{K} q\|q\|^{n-1}\left(C_{\mathrm{OH}}\right)^{r} d^{-p} \exp \left(-\frac{E+p \Omega}{R T}\right),
$$

where $A_{K}$ is a pre-exponential factor, $q=\sigma-2 G_{\mathrm{K}} \epsilon_{\mathrm{K}}$ is the effective stress, and $G_{K}$ is strain-hardening coefficient. This rheological framework has been useful to model postseismic deformation (e.g., Nur and Mavko 1974; Savage 2000; Hirahara 2002; Freed and Bürgmann 2004; $\mathrm{Hu}$ et al. 2004; Hetland and Hager 2005; Wang 2007; Pollitz et al. 2008; Johnson et al. 2009; Suito and Freymueller 2009; Wang et al. 2012; Sun 2014; Hu et al. 2016; Klein et al. 2016; Li et al. 2017; Muto et al. 2011, and references therein). In this study, we approximate the rheological response by the steady-state, as the details of sub-annual evolution of viscoelastic relaxation is not of central importance to our discussion.

\section{Governing equations}

We consider the dynamics of fault slip and viscoelastic flow during the seismic cycle within the quasi-dynamic approximation (Tse and Rice 1986; Rice and Tse 1986; Rice et al. 2001), whereby the wave-mediated stress transfer is ignored. In a viscoelastic medium, the traction along the fault depends on both the velocity of the surrounding fault elements and the anelastic strain-rate in the surrounding rocks. The rate of change of shear traction due to fault slip (e.g., Maruyama 1964; Rice and Tse 1986; Shibazaki and Matsu'ura 1992; Kato 2003; Ziv and Cochard 2006; Fukuyama 2007) is extended to include the effect of viscoelastic flow as follows

$$
\dot{\tau}=\int_{\partial \Gamma} \mathbf{K} \cdot\left(\mathbf{v}-\mathbf{v}_{L}\right) \mathrm{d} A+\int_{\Delta} \mathbf{J} \cdot\left(\dot{\boldsymbol{\epsilon}}-\dot{\boldsymbol{\epsilon}}_{L}\right) \mathrm{d} V-\frac{G}{2 V_{S}} \dot{V},
$$


where $\mathbf{K}$ is the Green's function tensor for self-interactions on the fault surface $\partial \Gamma$ (e.g., Chinnery 1963; Okada 1992; Segall 2010; Gimbutas et al. 2012; Nikkhoo and Walter 2015), $\mathbf{v}$ is the instantaneous velocity vector, $\mathbf{v}_{L}$ is the local loading rate on the fault, $\dot{\boldsymbol{\epsilon}}$ represents the anelastic strain-rate tensor in the ductile domain $\Delta$, and $\mathbf{J}$ is the Green's function tensor describing how distributed deformation affects the shear stress on the fault (Faivre 1969; Chiu 1978; Nozaki and Taya 2001; Kuvshinov 2008; Barbot et al. 2017; Barbot 2018a). The last term on the right-hand side corresponds to the radiation-damping term with the rigidity $G$, shear wave velocity $V_{S}$ and slip acceleration $\dot{V}$ (Rice and Tse 1986; Tse and Rice 1986; Rice et al. 2001).

Viscoelastic deformation is controlled by the amplitude and orientation of stress. Following a decomposition of the total strain into the elastic and anelastic components (Andrews 1976; Barbot and Fialko 2010), the evolution of the deviatoric stress tensor in the viscoelastic substrate can be written

$$
\dot{\boldsymbol{\sigma}}=\int_{\Delta} \mathbf{M} \cdot\left(\dot{\boldsymbol{\epsilon}}-\dot{\boldsymbol{\epsilon}}_{L}\right) \mathrm{d} V+\int_{\partial \Gamma} \mathbf{L} \cdot\left(\mathbf{v}-\mathbf{v}_{L}\right) \mathrm{d} A,
$$

where $\mathbf{M}$ is the Green's function for self stress in the ductile substrate and $\mathbf{L}$ represents the stress impacted by fault slip onto the ductile rocks. Therefore, the Green's functions $\mathbf{J}$ and $\mathbf{L}$ represent the mechanical coupling between brittle and ductile deformation. The terms $\mathbf{v}_{L}$ and $\dot{\boldsymbol{\epsilon}}_{L}$ represent the long-term slip-rate on the fault and the long-term strain-rate in the viscoelastic substrate, respectively, and are considered constants imposed by long-term geodynamics. Combining the constitutive laws (3), (4), and (5) with the governing equations (7) and (8) allows us to simulate the dynamics of fault slip coupled with viscoelastic flow.

Several numerical approaches have been proposed to incorporate nonlinear viscoelastic flow in seismic cycle simulations, including the finite-difference and finite-elements methods (Herrendörfer et al. 2015; Erickson et al. 2017; Sobolev and Muldashev 2017; Biemiller and Lavier 2017; Allison and Dunham 2018; Tong and Lavier 2018). Here, we use the integral method proposed by Lambert and Barbot (2016) and Barbot (2018b), whereby the fault surface is discretized into line elements and the ductile domain is meshed with surface elements in crosssection (Barbot et al. 2017; Barbot 2018a). The integrals in Eqs. (7) and (8) can then be evaluated numerically with algebraic relationships. The approach allows us to include non-planar fault geometry (Ong et al. 2019) and to accommodate nonlinear rheological laws. The dynamics of fault slip coupled with viscoelastic flow is then obtained based on the Runge-Kutta method with adaptive time steps (Press et al. 1992). Some aspects of the numerical method have been validated against other tools (Erickson et al. 2020).

\section{Take-away from dimensional analysis}

A dimensional analysis of the governing equation for fault slip can help identify four dimensionless variables that control the rupture style and other characteristics of the seismic cycle in isothermal conditions (Barbot 2019b). Non-dimensional parameters are important to consider because they reduce the parameter space considerably: various combinations of physical parameters producing the same set of non-dimensional parameters are expected to produce similar rupture styles, only with different recurrence times or overall size. The static friction parameter $\mu_{0}$ controls the overall fault strength and affects the rupture style. In particular, weak faults can rupture in anomalously long and complex ruptures. Another parameter $V_{\text {th }}=2 V_{S}(b-a) \bar{\sigma} / G$, linked to seismic wave radiation, controls the peak velocity and the rupture velocity during fast ruptures (Barbot 2019b). This parameter affects the accretionary prism in subduction zones particularly because of the low shear wave speeds of water-saturated sedimentary muds. The remaining two non-dimensional parameters $R_{u}$ and $R_{b}$ represent important degrees of freedom because they vary wildly in nature and play important roles in controlling fault dynamics. The Dieterich-Ruina-Rice number

$$
R_{u}=\frac{(b-a) \bar{\sigma}}{G} \frac{W}{L},
$$

where $G$ is the rock rigidity, $W$ is a representative length scale of the fault segment, and $a$ and $b$ are defined in Eqs. (1) and (2), controls the importance of non-local stress transfer. The $R_{u}$ number can be shown to represent a ratio of segment size to nucleation size (Barbot 2019b). The $R_{b}$ number

$$
R_{b}=\frac{b-a}{b}
$$

controls the relative importance of the transient evolutionary effects, i.e., the weakening and strengthening with contact rejuvenation and contact aging, respectively. The $R_{b}$ number also controls the ratio of static and dynamic stress drops during rupture, and hence the amount of fracture energy consumed. The $R_{u}$ and $R_{b}$ numbers form a two-dimensional phase space, each coordinate being associated with a potentially different rupture style. Large $R_{u}$ numbers promote complexity of the seismic cycle, with a wide range of rupture sizes (Wu and Chen 2014; Cattania and Segall 2018; Cattania 2019). Low $R_{u}$ numbers correspond to increasing stability of the fault patch, i.e., a propensity for cycles of slow earthquakes, slow-slip 
events, or creep, depending on the actual value. Low $R_{b}$ numbers also promote macroscopic stability, but a combination of large $R_{u}$ and low $R_{b}$ leads to chaotic cycles of slow-slip events encompassing slow earthquakes (Barbot 2019b). During model design, we choose the physical parameters considering the predicted dynamics associated with the corresponding set of non-dimensional parameters and their coordinates in phase space.

\section{Model description and physical parameters}

We design a numerical simulation of short-term subduction dynamics that incarnates the structural model presented in the previous Section. The model allows us to discuss the emergence of a wide range of rupture styles, each associated with a specific megathrust segment, and to illuminate the nonlinear coupling among the various domains of the megathrust and surrounding viscous substrate. For numerical convenience, we consider a two-dimensional approximation in plane-strain conditions along a trench-perpendicular cross-section of the Nankai Trough (Fig. 2). The model is complex enough to discuss general aspects of fault dynamics in this region, but the reader is referred to even more sophisticated models of the Nankai Trough (Hori et al. 2004; Hori 2006; Matsuzawa et al. 2010; Shibazaki et al. 2012; Matsuzawa et al. 2013; Hyodo and Hori 2013). We follow the megathrust geometry from the Slab1.0 model (Hayes et al. 2012) along the profile P-P' in Fig. 1. We extend the slab geometry down to more than $200 \mathrm{~km}$ depth, even though the deepest section is not observed seismologically (Nakajima and Hasegawa 2007; Hirose et al. 2008; Hayes et al. 2018). We divide the megathrust into five segments with piecewise constant dip angles. The physical parameters at each segment are determined considering the lithology and temperature at the plate interface as well as the expected dynamics based on the resulting non-dimensional number in the governing equations. Because of numerical limitations, we adopt a uniform rigidity $G=30 \mathrm{GPa}$, shear wave speed $V_{S}=3000 \mathrm{~m} / \mathrm{s}$, and Poisson's ratio $v=0.25$. This prevents us from using more realistic variations, in particular, in the accretionary prism, where low rigidity plays an important role (Sallarès and Ranero 2019). The spatial distribution of the relevant physical parameters is compiled in Table 1.

For segment A, we use a low static friction coefficient $\mu_{0}=0.1$, compatible with the presence of poorly consolidated material in the overlying sediment pile-up. Clay minerals also exhibit velocity-weakening behavior under low normal stress and low loading rate. For simplicity, we conflate the accretionary prism and the frontal prism into one single region of uniform properties. We also ignore the change of frictional properties associated with the smectite to illite transition (Saffer and Marone 2003). The local loading rate on the megathrust $V_{\mathrm{L}}=1.2 \times 10^{-9} \mathrm{~m} / \mathrm{s}$, is smaller than the plate convergence of $V_{\mathrm{pl}}=1.8 \times 10^{-9} \mathrm{~m} / \mathrm{s}$ to account for the partitioning of deformation among the megathrust, thrusts, and folds of the sedimentary wedge (Sathiakumar et al. 2020). Using the down-dip width of the megathrust that intersects with the accretionary wedge, i.e., $W=41.75 \mathrm{~km}$, and the frictional properties shown in Table 1 , the resulting non-dimensional parameters $R_{u}=1.82$ and $R_{b}=0.025$ are associated with a complex long-term slow-slip regime (Barbot 2019b). All other segments have $V_{\mathrm{L}}=V_{\mathrm{pl}}$.

In the seismogenic zone (segment $B$ ), we select a set of physical parameters that produces large ruptures within the recurrence period of the Nankai earthquakes, which vary within $140 \pm 42$ years (Ando 1975; Rikitake 1976; Thatcher 1984; Kumagai 1996). In addition, we choose the frictional properties to obtain complex seismic sequences with full and partial ruptures of the seismogenic zone, which occurs for $R_{u} \geq 16$ for a single asperity embedded in a planar fault (Barbot 2019b). Using $W=148.75 \mathrm{~km}$ as the characteristic length scale of the seismogenic zone and with the combination of effective normal stress, characteristic weakening distance, and kinematic friction coefficients, we obtain $R_{u}=29.7$, a value high enough to generate complex seismic cycles with a variety of rupture sizes.

In the metamorphic belt (segment $\mathrm{C}$ ), we choose a set of frictional properties that reflects stable weakening and the emergence of long-term slow-slip events with recurrence times of about 2 years and rupture durations of several months. As discussed in the introduction, this can be obtained with a variety of mechanisms that permit nucleation but inhibit fast slip. For simplicity, we adopt a simple frictional behavior with physical properties such that $R_{u}=1.75$ and $R_{b}=0.18$, a near-stable regime of periodic slow slip (Barbot 2019b). The low $R_{b}$ number associated with near velocity-neutral conditions is justified by the gradual transition from velocity-weakening to velocity-strengthening properties as temperature increases with depth. After we added other velocityweakening segments to the model, the recurrence time of the long-term slow-slip events can be extended to about 2 to 6 years, consistent with the observations in different regions along the strike of the Nankai Trough (Hirose et al. 1999; Hirose and Obara 2005; Yarai and Ozawa 2013; Kobayashi 2014).

In the mantle lid (segment D), we consider frictional properties that produce a chaotic form of slow-slip events, whereby macroscopic slow slip is accompanied by slow earthquakes. This phenomenon emerges from the nonlinear dynamics of fault slip and was identified 
Table 1 Summary of the physical parameters controlling fault dynamics and viscoelastic flow

\begin{tabular}{|c|c|c|}
\hline \multicolumn{3}{|l|}{ Segment A-accretionary prism } \\
\hline Static friction coefficient & $\mu$ & 0.1 \\
\hline Effective normal stress & $\bar{\sigma}$ & $35 \mathrm{MPa}$ \\
\hline Direct-effect parameter & $a$ & $5.85 \times 10^{-2}$ \\
\hline Steady-state parameter (velocity-weakening) & $b-a$ & $1.5 \times 10^{-3}$ \\
\hline Characteristic weakening distance & L & $4 \mathrm{~cm}$ \\
\hline Loading rate & $V_{L}$ & $1.2 \times 10^{-9} \mathrm{~m} / \mathrm{s}$ \\
\hline Segment width & w & $41.75 \mathrm{~km}$ \\
\hline \multicolumn{3}{|l|}{ Segment B-seismogenic zone } \\
\hline Static friction coefficient & $\mu$ & 0.6 \\
\hline Effective normal stress & $\bar{\sigma}$ & $20 \mathrm{MPa}$ \\
\hline Direct-effect parameter & $a$ & $7.6 \times 10^{-3}$ \\
\hline Steady-state parameter (velocity-weakening) & $b-a$ & $2.4 \times 10^{-3}$ \\
\hline Characteristic weakening distance & L & $8 \mathrm{~mm}$ \\
\hline Loading rate & $V_{\mathrm{L}}$ & $1.8 \times 10^{-9} \mathrm{~m} / \mathrm{s}$ \\
\hline Segment width & w & $148.75 \mathrm{~km}$ \\
\hline \multicolumn{3}{|l|}{ Segment C-metamorphic belt (mantle wedge corner) } \\
\hline Static friction coefficient & $\mu$ & 0.6 \\
\hline Effective normal stress & $\bar{\sigma}$ & $20 \mathrm{MPa}$ \\
\hline Direct-effect parameter & $a$ & $2 \times 10^{-3}$ \\
\hline Steady-state parameter (velocity-weakening) & $b-a$ & $4.5 \times 10^{-4}$ \\
\hline Characteristic weakening distance & L & $4.1 \mathrm{~mm}$ \\
\hline Loading rate & $V_{L}$ & $1.8 \times 10^{-9} \mathrm{~m} / \mathrm{s}$ \\
\hline Segment width & W & $24 \mathrm{~km}$ \\
\hline \multicolumn{3}{|l|}{ Segment D-mantle lid } \\
\hline Static friction coefficient & $\mu$ & 0.6 \\
\hline Effective normal stress & $\bar{\sigma}$ & $20 \mathrm{MPa}$ \\
\hline Direct-effect parameter & $a$ & $2 \times 10^{-3}$ \\
\hline Steady-state parameter (weakening near velocity-neutral) & $b-a$ & $2 \times 10^{-4}$ \\
\hline Characteristic weakening distance & L & $0.7 \mathrm{~mm}$ \\
\hline Loading rate & $V_{\mathrm{L}}$ & $1.8 \times 10^{-9} \mathrm{~m} / \mathrm{s}$ \\
\hline Segment width & W & $32 \mathrm{~km}$ \\
\hline \multicolumn{3}{|l|}{ Segment $\mathrm{E}$-mantle wedge } \\
\hline Static friction coefficient & $\mu$ & 0.6 \\
\hline Effective normal stress & $\bar{\sigma}$ & $40 \mathrm{MPa}$ \\
\hline Direct-effect parameter & $a$ & $1 \times 10^{-2}$ \\
\hline Steady-state parameter (velocity-strengthening) & $a-b$ & $2 \times 10^{-3}$ \\
\hline Characteristic weakening distance & L & $2.5 \mathrm{~cm}$ \\
\hline Loading rate & $V_{\mathrm{L}}$ & $1.8 \times 10^{-9} \mathrm{~m} / \mathrm{s}$ \\
\hline Segment width & W & $53.5 \mathrm{~km}$ \\
\hline \multicolumn{3}{|l|}{ Viscoelastic substrate-upper mantle, oceanic asthenosphere } \\
\hline Background strain rate & $\dot{\varepsilon}_{22}^{0}$ & $-10^{-15} s^{-1}$ \\
\hline Basal mantle temperature & $T$ & $1673 \mathrm{~K}$ \\
\hline Prefactor & $A$ & $90 \mathrm{MPa}^{-n} \mathrm{~s}^{-1}\left(\mathrm{ppm} \mathrm{H}_{\mathrm{Si}}\right)^{-r}$ \\
\hline Power-law stress exponent & $n$ & 3.5 \\
\hline Activation energy & E & $460 \mathrm{~kJ} / \mathrm{mol}$ \\
\hline Activation volume & $\Omega$ & $11 \times 10^{-6} \mathrm{~m}^{3} / \mathrm{mol}$ \\
\hline Water content & $\mathrm{COH}_{\mathrm{OH}}$ & $1000(\mathrm{ppm} \mathrm{H} / \mathrm{Si})$ \\
\hline Water content exponent & r & 1.2 \\
\hline
\end{tabular}

The model assumes uniform elastic properties with a shear modulus of $G=30 \mathrm{GPa}$, Poisson's ratio $v=0.25$, and shear wave speed $V_{S}=3 \times 10^{3} \mathrm{~m} / \mathrm{s}$. The reference slip velocity is $V_{0}=10^{-6} \mathrm{~m} / \mathrm{s}$ 
in studies of rupture nucleation (Viesca 2016a, b) and seismic cycles (Barbot 2019b). Chaotic slow-slip cycles occurs in near velocity-neutral conditions, i.e., close to the stability transition forced by high ambient temperatures. We also consider kinematic friction properties and effective normal stress to produce slow-slip events every about 1 year with ruptures that last several weeks. Using the width of the velocity-weakening intersection of the megathrust with the upper mantle, $W=32 \mathrm{~km}$, we arrive at $R_{u}=6.1$ and $R_{b}=0.09$. The lower $R_{b}$ number than in the up-dip segment is justified by a greater proximity to the velocity-weakening to velocity-strengthening transition, which is likely an isotherm. This combination of the $R_{u}$ and $R_{b}$ numbers produces complex slow-slip events encompassing slow earthquakes (Barbot 2019b).

In section $\mathrm{E}$, further down-dip, the slab dives deeper into the mantle and the increasing temperature results in a long $(W=53.3 \mathrm{~km})$ velocity-strengthening segment. The frictional contact ends at the brittle-ductile transition at a depth of $71 \mathrm{~km}$ (the difference in depth from the volcanic arc originates from the absence of topography in the numerical model). For simplicity, we assume the same viscoelastic properties for the mantle wedge and the oceanic mantle, ignoring a more realistic contrast in water content and temperature. The temperature profile follows the cooling half-space model with a plate age of $60 \mathrm{Myr}$, and a basal mantle temperature of $1673 \mathrm{~K}$. We use the viscoelastic properties for dislocation creep of wet olivine with $1000 \mathrm{ppm} \mathrm{H/Si}$ (Hirth and Kohlstedt 2003). We ignore viscoelastic flow in the arc lower crust. We drive viscoelastic flow with the non-zero background shortening rate $\epsilon_{22}=-10^{-15} / \mathrm{s}$, where the subscripts 2 and 3 represent the $x_{2}$ and $x_{3}$ coordinates in the horizontal and depth direction, respectively.

We discretize the fault with a mesh fine enough to resolve the smallest characteristic lengths of the problem, in particular nucleation size and cohesion size. We choose the final, uniform fault sampling size of $125 \mathrm{~m}$ with a numerical convergence test. In the ductile substrate, we refine the mesh to resolve the spatial distribution of the stress change caused by megathrust earthquakes. We use $10-\mathrm{km}$-sized cross-section volume elements. The ductile substrate is represented by an unstructured mesh of triangular elements (Barbot 2018a, b).

\section{System-level dynamics of a subduction megathrust}

The two-dimensional subduction model simulates the dynamics of the megathrust and the surrounding asthenosphere during seismic cycles, including full and partial ruptures of the seismogenic zone, foreshocks and aftershocks, shallow slow-slip events, deep long-term and short-term slow-slip events, creep and afterslip, and viscoelastic relaxation in the ductile substrate (Figs. 3, 4, 5, 6).
Megathrust dynamics in the fault area within or adjoining the accretionary prism is perhaps the most complex of the model. The slip deficit is released by a wide range of slip styles that include long-term creep waves, partial coupling, slow and fast creep, afterslip, slow-slip events, and slow earthquakes (Figs. 3 and 4). The 450-year window into the seismic cycle shows no cyclic pattern whatsoever. Every full or shallow rupture of the seismogenic zone is followed by a long-period afterslip in segment A that endures across multiple earthquake cycles, including across super-cycles that is defined as the period between two full ruptures. The long afterslip response is better characterized as a long-term creep wave. In the interseismic period, creep propagates into the seismogenic zone from the top, resulting in the occurrence of slowslip events of increasing sizes. Some events culminate to a partial shallow rupture of the seismogenic zone. During the few years that precede full or shallow earthquakes, the shallow megathrust appears to creep near or at a fraction of plate rate. In general, the creep velocity is not uniform in the accretionary region, exhibiting a complex spatial pattern of partial locking.

Rupture dynamics in the seismogenic zone is also complex, inherently due to the high $R_{u}$ number, but also because of interactions with the quasi-stable accretionary prism and the slow-slip region. The megathrust generates earthquake super-cycles, defined here as the period separating two full ruptures of the seismogenic zone, with repeating periods varying from 30 to 180 years, with most super-cycles taking 120 years. Within a super-cycle, the recurrence time of full and partial ruptures-aftershocks excluded-is irregular, ranging from 10 to 75 years. Most earthquakes nucleate near the top and bottom boundaries of the seismogenic zone due to concentrated shear stress caused by creep or slow slip in the neighboring segments. A shallow foreshock sequence sometimes precede a full rupture, for example, the shallow events leading up to full rupture 54 (Fig. 6). All earthquakes are followed by afterslip on the deep megathrust and viscoelastic relaxation in the oceanic asthenosphere and the mantle wedge. Event 46 represents an aftershock of a full rupture (event 45).

Long-term and short-term slow-slip events recur every 4 years and 11 months, respectively. But the overall dynamics of slow-slip events is complex due to the systematic interaction of the short-term and long-term slow-slip regions, the trench-ward migration of the coupling boundary, and the long-term modulation by seismogenic zone ruptures. The model illuminates a range of interactions between the seismogenic zone and the slowslip region. Most of the great earthquakes that rupture the entire seismogenic zone penetrate through the down-dip slow-slip region. However, the full ruptures that initiate at 


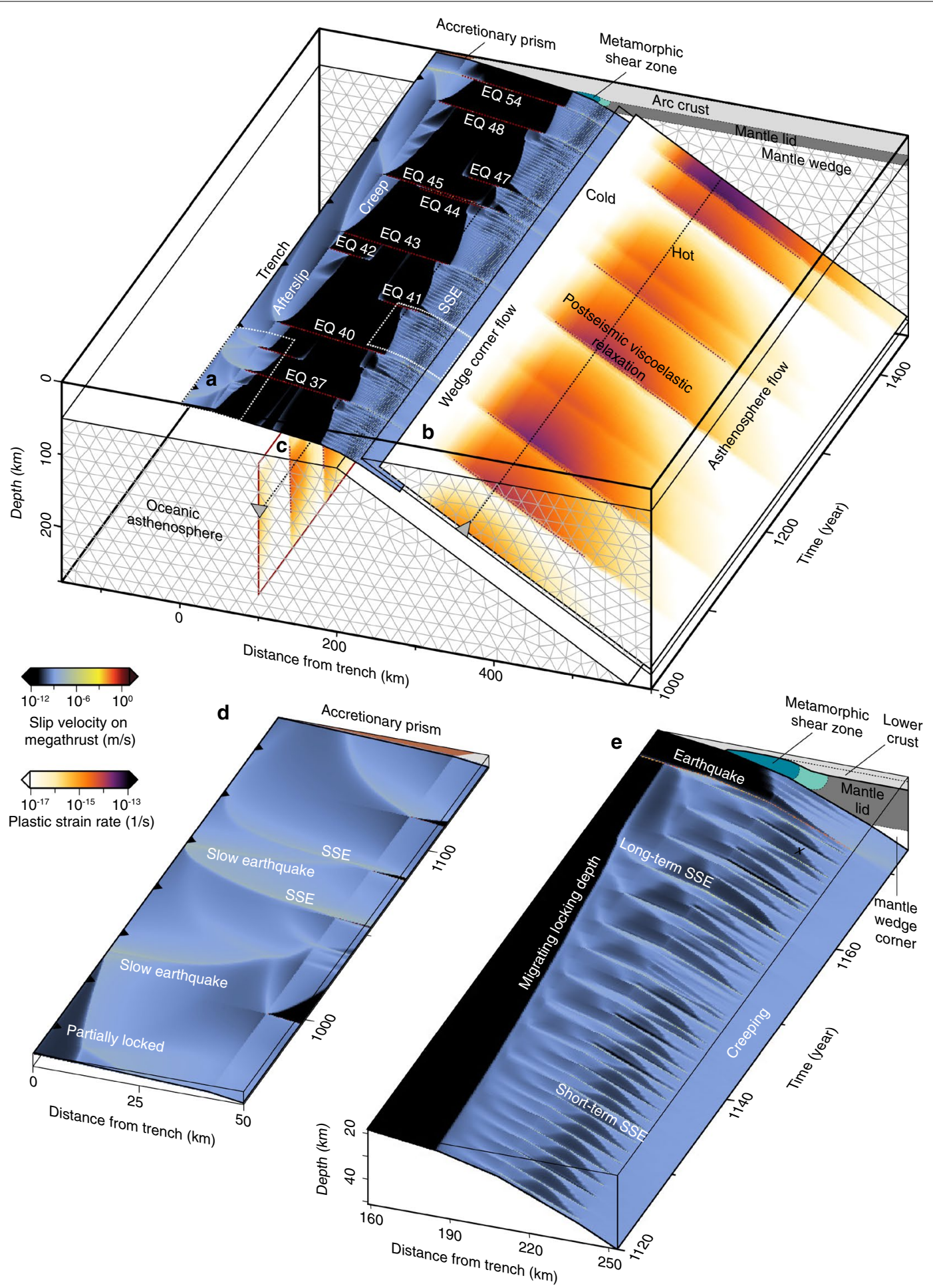

Fig. 3 Space-time evolution of brittle and ductile dynamics in a model subduction zone. a The fault dynamics showcases full and partial ruptures, long-term and short-term slow-slip events, and afterslip. The shallow section is characterized by non-stationary dynamics, with afterslip, creep waves, and long-term variations of partial locking. b, c The viscoelastic flow is modulated by the stress change impacted by large ruptures. The periods of viscoelastic relaxation are followed by periods of strain-deficit accumulation late in the interseismic period. $\mathbf{d}$ Dynamics of the shallow segment underneath the accretionary prism. e Dynamics of interacting long-term and short-term slow-slip events with fast ruptures in the seismogenic zone 
(See figure on next page.)

Fig. 4 a History of slip velocities at the center of each megathrust segment. b Afterslip, slow earthquakes and slow-slip events in the accretionary prism. c Full and partial ruptures break the locked seismogenic zone with varying recurrence intervals. $\mathbf{d}$ Long-term slow-slip events in the metamorphic belt at down-dip of the seismogenic zone. e Short-term slow-slip events in the mantle lid. $\mathbf{f}$ Creeping in the mantle wedge corner interrupted by afterslip following full and partial ruptures. $\mathbf{g}$ Overall peak slip velocity on the megathrust, which captures events that do not rupture the segment centers. $\mathbf{h}$ The strain rate evolution of the volume element shown as the gray triangle in the mantle wedge in Fig. 3. $\mathbf{i}$ The strain rate evolution of the volume element shown as the gray triangle in the oceanic mantle in Fig. 3. The indices of ruptures are consistent among figures

shallow depth sometimes terminate before reaching the down-dip boundary of the seismogenic zone and do not propagate into the slow-slip region. For example, the full ruptures 43 and 54 stretch from the up-dip boundary of seismogenic zone to the down-dip boundary of the slowslip region, but full rupture 45 instead triggers a deep aftershock in the slow-slip region (Fig. 6). During a supercycle, the shallow partial ruptures arrest within the seismogenic zone and all deep partial ruptures penetrate into the slow-slip region. All ruptures that propagate in the slow-slip region greatly perturb the recurrence pattern of slow-slip events, sometimes for decades. The long-term slow-slip region is the most frequently and most durably affected due to its proximity with the seismogenic zone.

The recurrence pattern of slow-slip events is perturbed by interactions between the short-term and long-term slow-slip events and interseismic migration of the locking depth. As the locking depth of the seismogenic zone slowly migrates towards the trench, the width of the creeping section is expanded up-dip of segment $C$, leading to expansion of the long-term slow-slip ruptures (Figs. 3e, 4c). The short-term slow-slip events have stable peak slip rates and recurrence times in the early stage. However, the slowly expanding long-term slow-slip events eventually affects the short-term slow-slip events, which exhibit greater variability in slip rates and recurrence intervals in the later stage of the interseismic period (Figs. 3e, 4d). As a result, the recurrence pattern of long-term and shortterm slow-slip events are opposite: the long-term slowslip events, closer to the seismogenic zone, are suppressed in the early stage of the seismic cycle, and correspondingly, the short-term slow-slip events are quasi-periodic. Later in the seismic cycle, long-term slow-slip events are well developed, and the short-term slow-slip events feature a complex, aperiodic cycle.

Due in part to the chaotic dynamics of slow slip in segment $\mathrm{D}$ induced by the coordinates of the physical parameters in phase space, the short-term slow-slip sequences exhibit tremendous complexity. This is exemplified in two slow-slip sequences that start at about 930 and 1093 years after the beginning of the simulation (Fig. 5). As the locking depth of the seismogenic zone migrates up-dip, the long-term slow-slip events in segment $\mathrm{C}$ are facilitated, triggering larger stress perturbation in segment $\mathrm{D}$ when it is expanding up-dip and down-dip (Fig. 5a, e). The slow slip reaching the segment boundary breaks into segment $\mathrm{D}$, generating a relatively rapid slow-slip event that propagates faster and bilaterally, lasting half an hour for the first sequence (Fig. 5d) or one day for the second sequence (Fig. 5h). A faster rupture nucleates immediately thereafter and breaks the entire locked section of segment $\mathrm{D}$, eventually triggering another slow-slip event (Fig. 5b, f) in segment C. The evolution of these two sequences of slow slip and slow earthquakes demonstrates that the migration of deep slow slip can facilitate the nucleation of adjacent slow earthquakes. Conversely, the propagation of slow earthquakes affects the pattern of long-term and short-term slow-slip events. These sequences are reminiscent of the slow slip transient that was excited during an episodic tremor and slip event at the down-dip extension of the locked zone beneath western Shikoku Island in Southwest Japan (Kano et al. 2019).

At greater depth, fault dynamics is much simpler, dominated by continuous creep at plate rate during most of the seismic cycle, but occasionally interrupted by afterslip following full and partial ruptures (Figs. 3a, 4f). The afterslip period consists of a short pulse of rapidly decaying creep that lasts a few years, as observed after all suitably instrumented large subduction earthquakes (e.g., Hsu et al. 2006; Chlieh 2007; Feng et al. 2016; Tsang et al. 2016; Bedford et al. 2016; Klein et al. 2016; Hu et al. 2016; Qiu et al. 2018; Tang et al. 2019; Muto et al. 2011).

In the upper mantle, a transient flow acceleration is triggered by the sudden stress perturbation induced by a full rupture or a deep partial rupture (Fig. 3b, c). Due to variable earthquake sizes and down-dip moment distribution, the peak postseismic strain-rate varies substantially. The full postseismic relaxation takes $50-150$ years and during some short interseismic periods the induced stress perturbation is not fully relaxed. During the postseismic transient, the effective viscosity decreases by one order of magnitude from its steady-state value (Figs. 2a, $7 \mathrm{a})$, consistent with the stress dependence of effective viscosity. The postseismic strain-rate components $\dot{\varepsilon}_{22}, \dot{\varepsilon}_{23}$ and $\dot{\varepsilon}_{33}$ increase to 50 times larger than the steady-state values, while the locations of the peak strain rates and their directions remain the same except for the region at a depth of 100 to $200 \mathrm{~km}$ below the deeper portion of the seismogenic zone and the slow-slip segments (Fig. 7). 


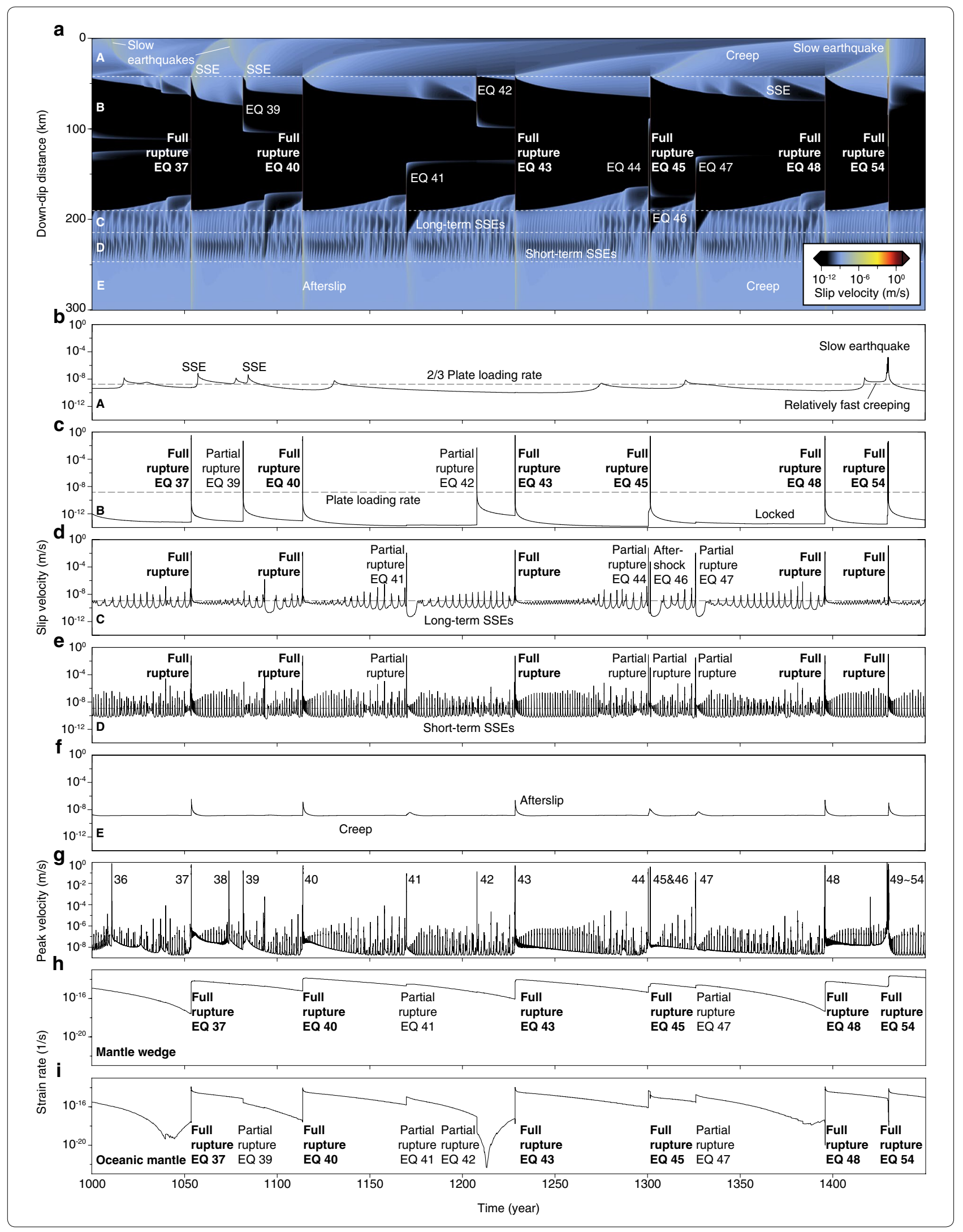




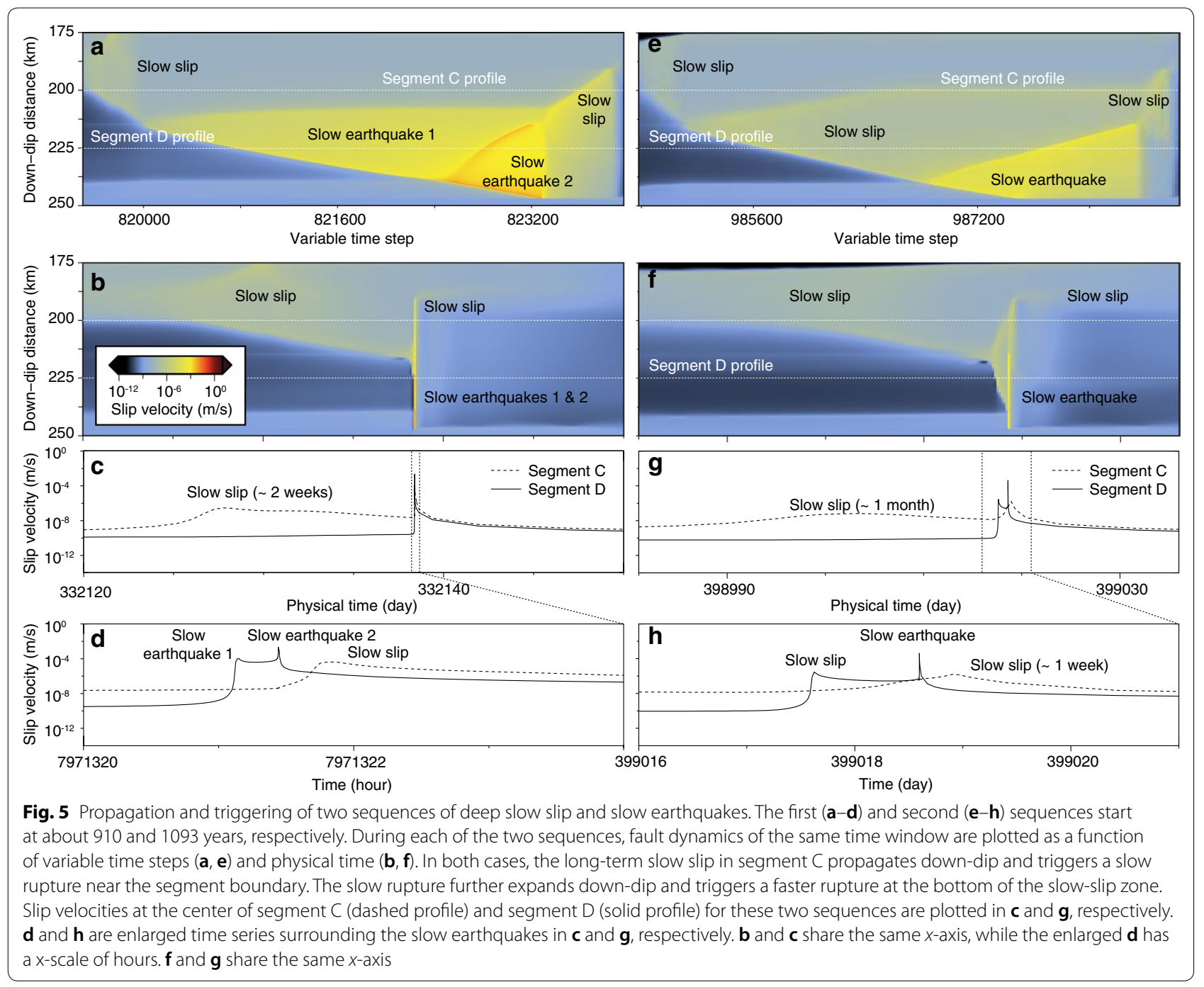

This feature is consistent with the deep SSEs frequently loading the viscoelastic substrate. In the particularly long earthquake cycles, the relaxation is followed by a slower flow with strain-rates lower than the background loading rate, which preserves the long-term imposed strain-rate on average in the asthenosphere.

\section{Surface dynamics}

Recent studies have illuminated the different contributions of megathrust slip and mantle flow in the dynamics of surface deformation (e.g., Barbot 2018b; Hu et al. 2016; Noda et al. 2018; Suito 2017; Sun 2014; Qiu et al. 2018; Agata et al. 2019; Weiss et al. 2019). In particular, the viscoelastic relaxation of the oceanic asthenosphere in these models generates retrograde horizontal displacements in the forearc during viscoelastic relaxation. We describe the surface dynamics by tracking the surface deformation deficit, i.e., the difference between the cumulative displacement and the long-term average throughout several earthquake super-cycles (Fig. 8). We compute the space-time distribution of surface displacement produced by fault slip and viscoelastic flow separately by multiplying the slip or strain in the regions of interest by the respective Green's function in a post-processing step. Overall, the fault slip contribution dominates the surface displacements above the megathrust, but its effect is concentrated in the forearc region and is reduced in the interseismic period because of re-locking of the seismogenic zone. Partial ruptures also produce sudden surface displacements. The complex behavior of the shallow segment generates long-term displacements in the accretionary prism and in the outer rise. Viscoelastic surface deformation is most rapid in the several years following large earthquakes, after which viscoelastic flow gradually returns to background rates in the following 50 to 80 years. The surface displacements produced by viscoelastic 


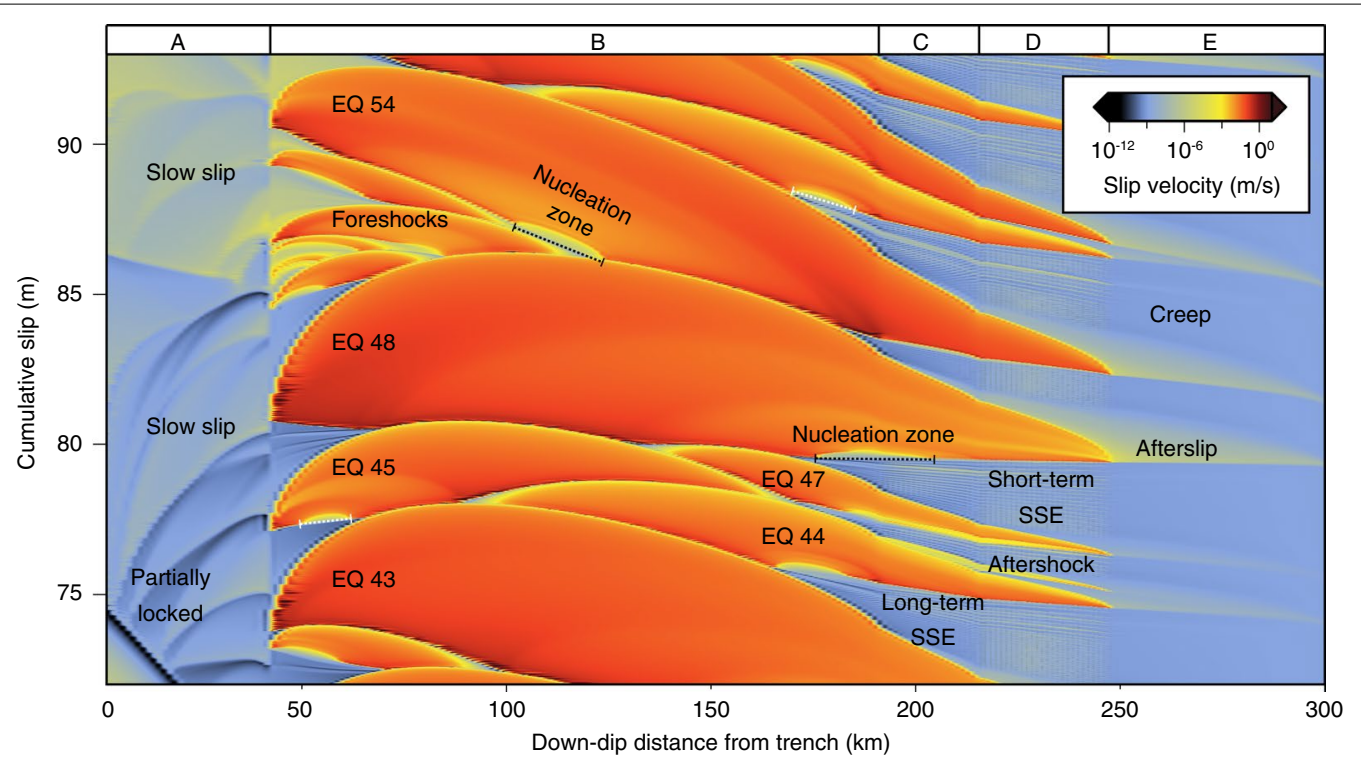

Fig. 6 Partition of slip modes along the megathrust. The accretionary prism (segment A) features partial locking, creep, and occasional slow slip. The seismogenic zone (segment B) shows stick slip with full and partial ruptures, foreshocks and aftershocks, with creep slowly migrating inwards during the interseismic period. Earthquake nucleation (dashed segments) occur up-dip and down-dip the seismogenic zone. Large ruptures can penetrate into the slow-slip segment. Some large ruptures with shallow hypocenters stop before they reach the down-dip boundary of the seismogenic zone, sometimes generating an aftershock in the slow-slip region. Small ruptures occur mostly near the boundaries of the seismogenic zone. The rupture indices are consistent among figures

flow are more distributed than those produced by fault slip, spreading across the outer-rise, forearc, and backarc regions. All earthquakes, afterslip, slow-slip events and creep produce seaward surface displacement. The viscoelastic relaxation produces retrograde motion in the forearc, most notably above the seismogenic zone. Note that the bottom of the seismogenic zone often coincides roughly with the continental slope, so this phenomenon may only be measured with seafloor geodesy.

The vertical component of the surface deformation shows spatial diversity that highly depends on the location of the source. The fault slip of a great earthquake produces substantial uplift above the major rupture area and subsidence in the region landward of the uplifted region (Fig. $8 \mathrm{~b}$, indicated by colors). The boundary of uplift and subsidence regions is about $150 \mathrm{~km}$ landward from trench. Partial ruptures produce a similar uplift and subsidence pattern, but its location varies with the distribution of coseismic slip. For example, the surface uplift and subsidence pattern created by event 47 , which occurs in the down-dip portion of the seismogenic zone, are farther from the trench than the patterns created by event 42 that occurs in the up-dip portion and the full rupture 43 (Fig. 8b). The deformation caused by viscoelastic flow is significant during the postseismic period, producing uplift within the region between 0 to $150 \mathrm{~km}$ landward from the trench and the volcanic arc region, and subsidence in the outer rise and within the region between 150 to $250 \mathrm{~km}$ from the trench (Fig. 8c). Some important details concerning the dynamics of surface deformation may vary among subduction zones depending on megathrust geometry, the age of the subducting plate, and the rheology of the mantle wedge, all of which affecting the mechanical response of the brittle-ductile system.

\section{System-level dynamics and impact of mechanical coupling}

In this section, we compare our coupled subduction model with simpler models where only one or a pair of velocity-weakening segments are included, assuming that the surrounding fault region is velocity strengthening. This allows us to identify the effect of the mechanical coupling between various nearby segments. First, we consider the case of a shallow velocity-weakening region that shares the characteristics of segment A, the accretionary prism. In this case, the shallow megathrust produces creep waves and long nucleations culminating in a slow earthquake (Fig. 9a). This behavior is compatible with the chaotic slow-slip events that emerge at low $R_{b}$ numbers, producing macroscopic slow-slip interspersed by short-duration slow earthquakes (Barbot 2019b). In contrast, the coupled model produces a wider range of behaviors at these depths, including slow-slip with slow 


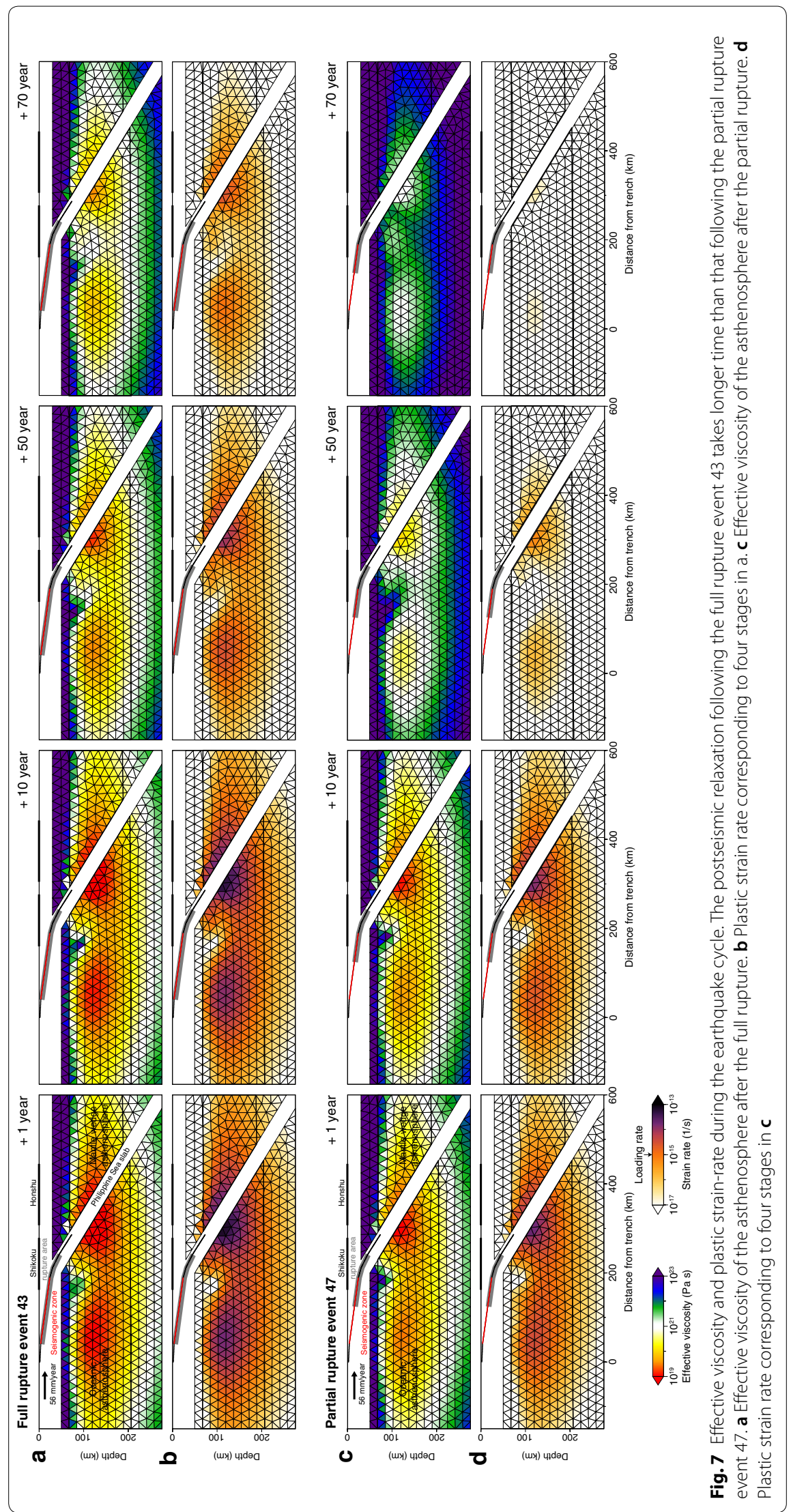




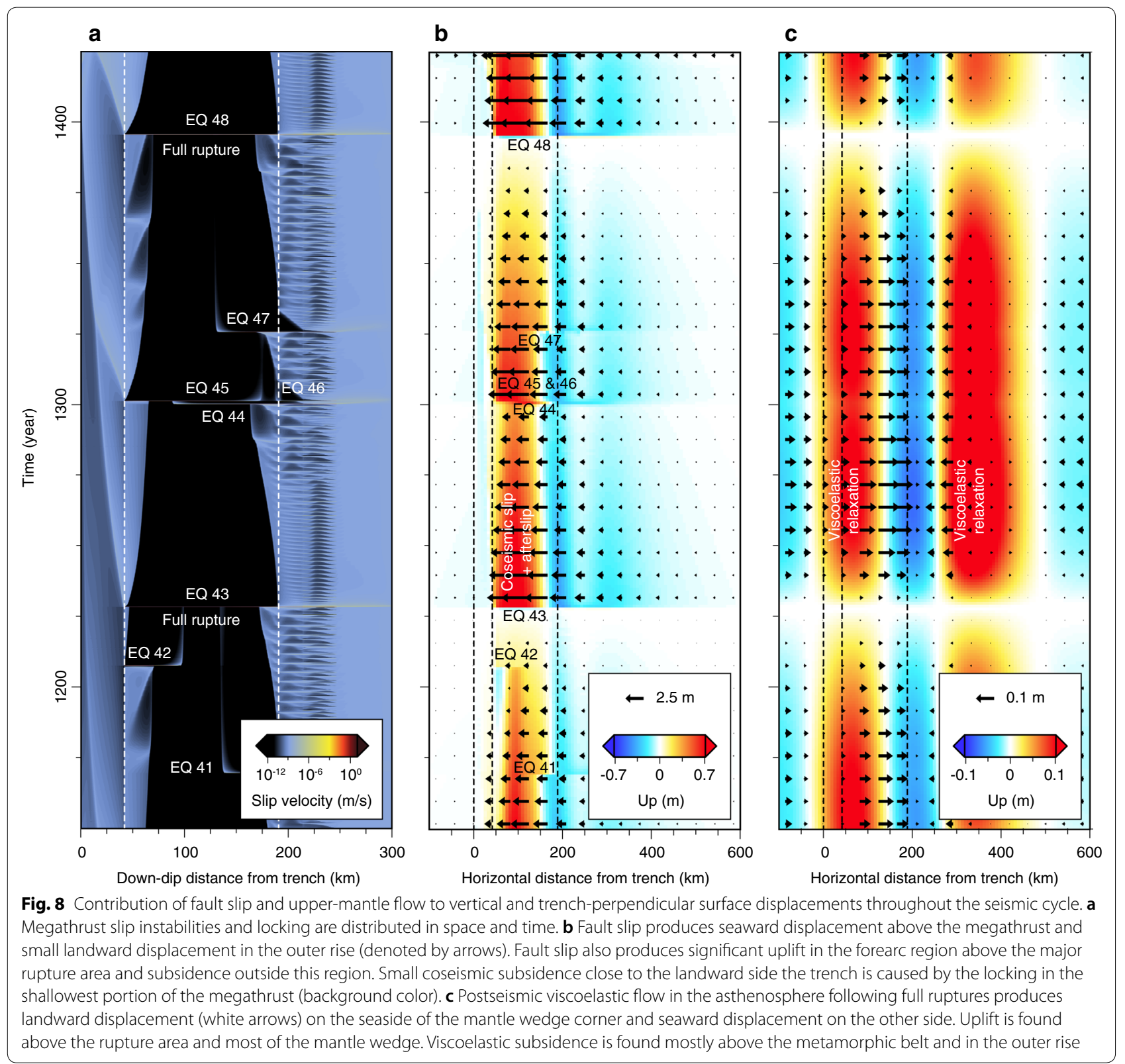

earthquakes, but also regular slow-slip events, long-term creep waves, and afterslip. This comparison illustrates the disruptive effect of the nearby seismogenic zone, which forces the relaxation of slip deficit in various modes during the interseismic period.

Next, we compare the coupled model with a simpler case where only the seismogenic zone is included. This is done by changing the friction property of segments A, $\mathrm{C}$, and D from velocity-weakening to velocity-strengthening, keeping the other friction parameters the same. The uncoupled model produces super-cycles of great regularity, where every event is followed by another in a complex, but quasi-periodic repeating sequence (Fig. 9b). The recurrence intervals of great earthquakes in the uncoupled model are about 95 years, while those in the coupled model vary from 70 to 115 in the period considered (Fig. 9d). The uncoupled model produces recurring partial ruptures during a super-cycle, while partial ruptures are not systematic in the coupled model. For example, there is no partial rupture during the second super-cycle of the period shown in Fig. 9d. The uncoupled model illustrates the complexity that spontaneously emerges from the nonlinear dynamics of fault slip for high $R_{u}$ numbers (e.g., Barbot 2019b; Cattania 2019). 

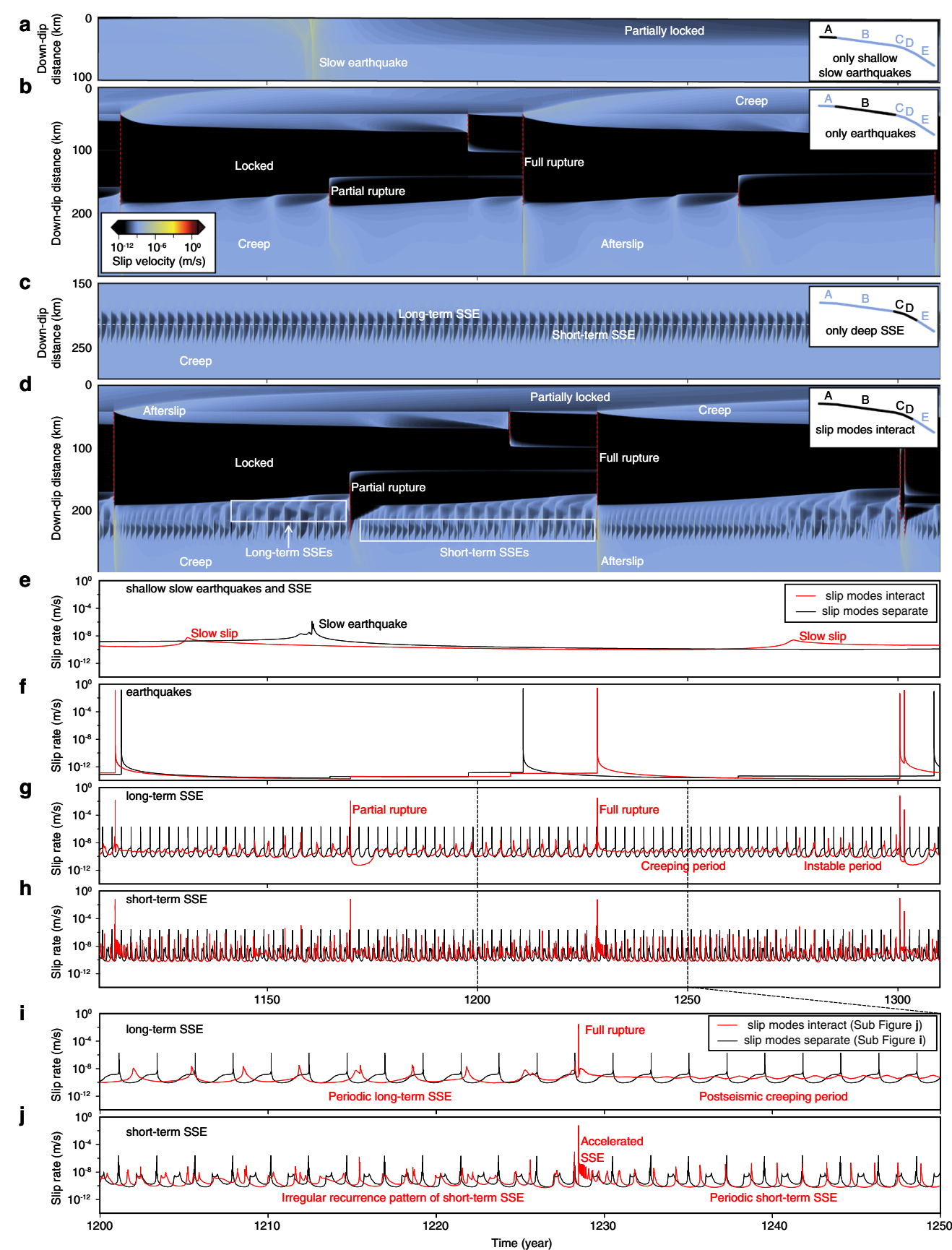

Fig. 9 Interactions between earthquakes and slow-slip events. a The model with velocity-weakening Segment A and velocity-strengthening down-dip segments produces slow-slip events every 490 years. $\mathbf{b}$ The model with a velocity-weakening seismogenic zone in the center and creeping neighboring segments produces periodic partial and full ruptures and afterslip propagating into the up-dip and down-dip segments. c The model with velocity-weakening segments $C$ and $D$, surrounded by creeping zones, produces periodic long-term and short-term slow-slip events. $\mathbf{d}$ The reference $2 \mathrm{D}$ subduction model with velocity-weakening segments in accretionary prism, seismogenic zone, metamorphic shear zone and mantle lid shows highly variable seismic cycles. e Only long-recurrence-time slow earthquakes are produced in the model with only velocity-weakening segment A, while long-term slow slip appears in the coupled model. f The coupled model shows less regular full ruptures. $\mathbf{g}$ The long-term slow-slip events in the coupled model are suppressed at the beginning and facilitated in the later stage of the interseismic period. $\mathbf{h}$ The short-term slow-slip events in the coupled model are accelerated after the earthquakes and their recurrence time and amplitudes are irregular in the later stage of the earthquake cycle. $\mathbf{i}$ and $\mathbf{j}$ are enlarged view of the deep slow-slip events between 1200 and 1250 years, they are corresponding to $\mathbf{g}$ and $\mathbf{h}$, respectively 
Additional complexity, in particular, aperiodic cycles, is obtained by mechanical coupling with the nearby velocity-weakening segments.

Finally, we examine the dynamics of another simple model where only the slow-slip events of segments $\mathrm{C}$ and $\mathrm{D}$ are included. The uncoupled model converges to a repeating period-two cycle of short-term and longterm slow-slip events (Fig. 9c). In comparison, the coupled model shows a reduced amplitude of the slow-slip events, possibly due to the locking of the seismogenic zone (Fig. 9e, f). Following great earthquakes or deep partial ruptures, afterslip propagates down-dip into the slow-slip region, weakening the fault segment and releasing the strain energy. The long-term slow-slip events are suppressed for 10 to 50 years, depending on the size of the earthquake (Fig. 9g). The short-term slow-slip events are accelerated for several years, after which they resume their natural recurrence pattern (Fig. 9h). The acceleration of short-term slow-slip events following a great earthquake is reminiscent of the increased tremors and slow-slip activity after the 2011 Tohoku-Oki earthquake (Nishikawa et al. 2019). As the long-term slow-slip events become more significant in the later stage of an earthquake cycle, they produce larger stress perturbation in the neighboring segments, which in turn leads to the variability of the recurrence time and amplitude of short-term slow-slip events. That slow-slip events in the metamorphic belt are inhibited in the decades following large earthquakes may explain the absence of recurring slow-slip observations in the Sunda trench. The series of recent Sumatra earthquakes, the 2004 Aceh-Andaman, the 2005 Nias, the 2007 Bengkulu earthquakes, may indeed have suppressed the slow-slip phenomenon in the region for several decades. If the model applies to the Sunda trench, slow-slip events should resume in the next decades.

\section{Seismic cycles modulated by viscoelastic flow}

With the model assumption of the viscoelastic flow presented in Table 1, the viscoelastic flow in upper mantle gradually modulates the earthquake super-cycle and the evolution of slow-slip events. This effect is illustrated by comparing the dynamics of the coupled model with another one where the upper mantle flow is preempted. In the latter, the fault slip is the only deformation mechanism included. We build earthquake catalogs for the two models and both of them show high variability in the size and recurrence time of earthquakes (Fig. 10a, b).

To represent the evolution of the super-cycle, the slip deficit at the center of the seismogenic zone, which is the difference between the cumulative slip and the long-term loading, are plotted for both models in Fig. 10c. The effect of viscoelastic flow accumulates for 5 super-cycles (560 years), after which it starts to modulate the short-term slow-slip events that are located in the deepest velocityweakening segment, also the closest to upper-mantle flow (Fig. 10f). The modulated short-term slow-slip behavior in turn decelerates long-term slow-slip events and influences earthquake cycles in the up-dip segments, amplifying the impact originated from viscoelastic flow (Fig. 10d, e).

The statistics of recurrence intervals of earthquakes and lengths of super-cycles are shown in Fig. 10g, h, respectively. With the cumulative effect from viscoelastic flow, the earthquake recurrence time shows a more random pattern, even though the most frequent recurrence time of $\sim 55$ years is the same in both cases. Surprisingly, the super-cycles modulated by asthenosphere flow are more concentrated, around 75 and 120 years. This could be related to the interactions between deep partial ruptures and slow-slip events. When long-term and short-term slow-slip events are decelerated by viscoelastic flow, the buildup of shear strain neighboring the slow-slip region may be slackened, which might delay a partial rupture that nucleates near the bottom of the seismogenic zone to the next super-cycle. For example, when viscoelastic flow in the asthenosphere is included, the full rupture events 32 and 33 occur consecutively (Fig. 10a) and the supercycle lasts a shorter period. When viscoelastic flow is not activated, partial ruptures always occur between two full ruptures (Fig. 10b), and the super-cycles span a longer period.

\section{Discussion}

Fault dynamics at subduction megathrusts is impacted by the structure, composition, and temperature of the rock assembly at the plate interface. A structural model such as the one described in the second Section provides the constitutive and boundary conditions for the seismic cycle, but tremendous complexity emerges from the nonlinear dynamics of frictional sliding, the interactions among fault segments, and the coupling between brittle and ductile deformation. The simulations of megathrust dynamics illustrate the system-level behavior of a complex mechanical system. Analyses of simpler architectures provide useful insights, for example, how ruptures styles can be associated with certain combinations of physical and geometrical parameters. However, some unique behaviors only unfold with added structural complexity. The presence of fault bends, the triggering of neighboring segments, and the long-range interactions between the brittle lithosphere and the ductile asthenosphere play an important role.

Despite the emerging complexity, the structural boundaries provide a virtually permanent setup that bounds the overall mechanical behavior. The slow-slip events are 


\section{a}

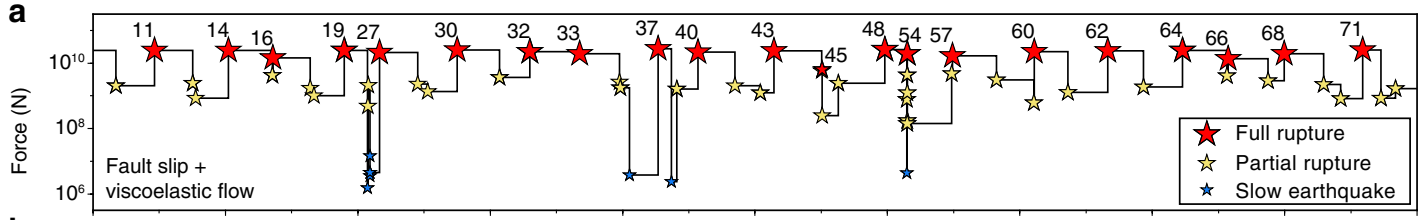

b
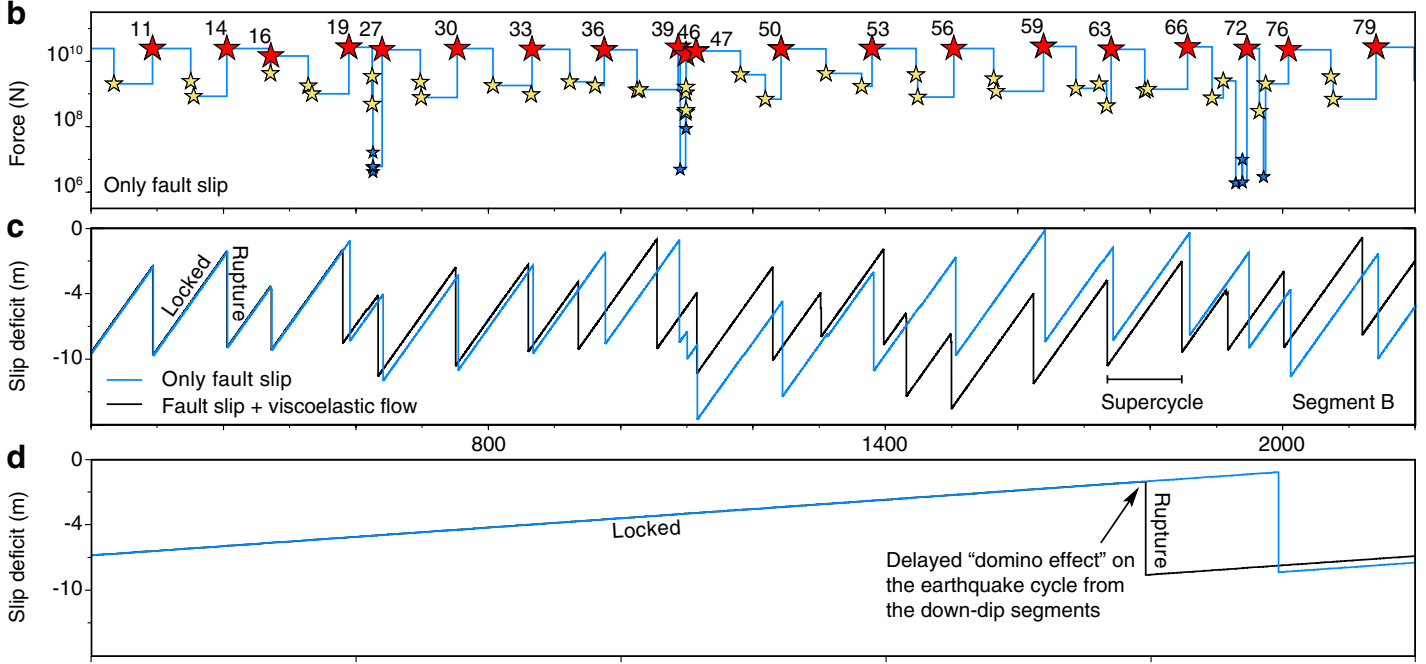

e

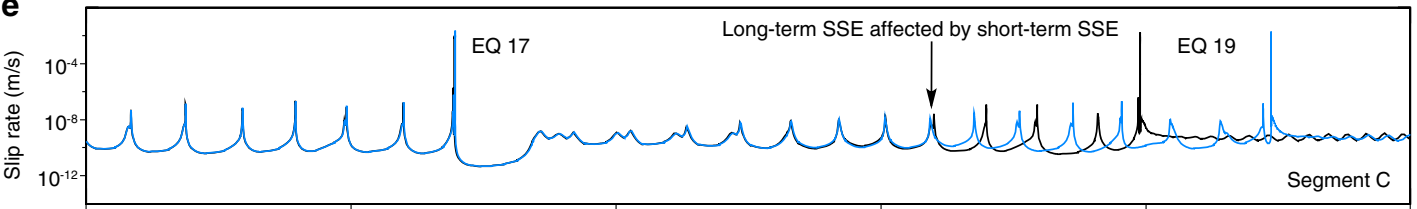

f
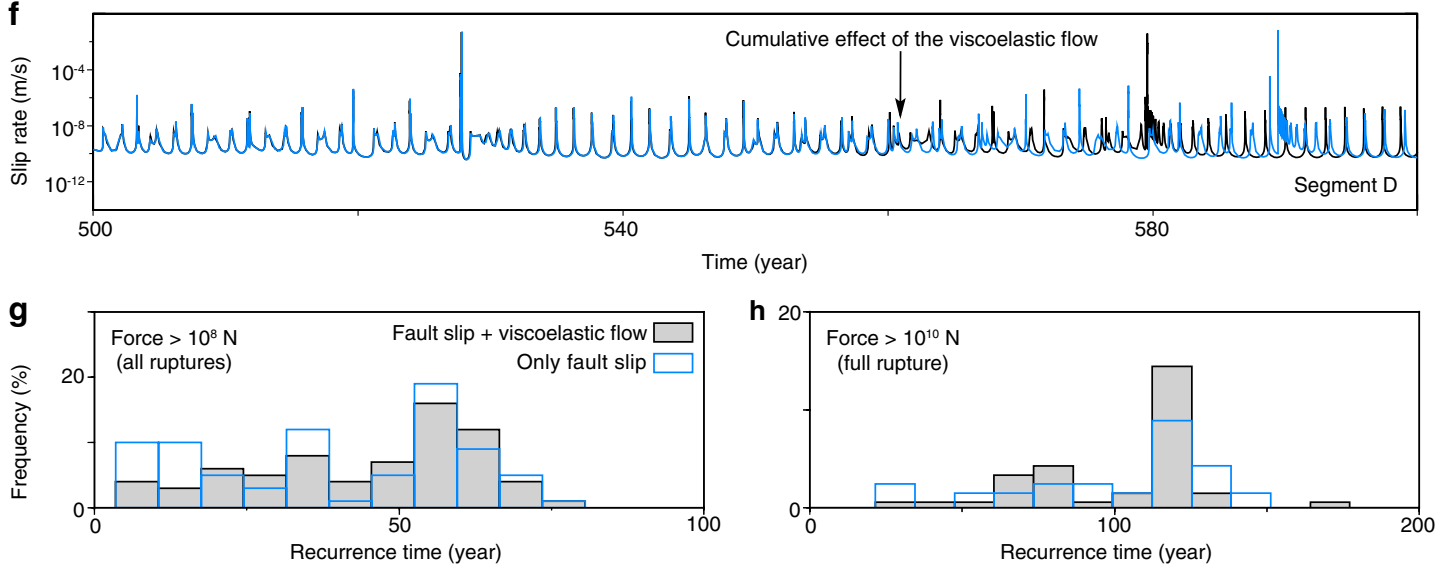

Fig. 10 Impact of asthenospheric flow on the seismic and slow-slip cycles. a The earthquake catalog from the simulation with coupled brittle and ductile deformation. Great earthquakes (red stars with event numbers) corresponding to full rupture of the seismogenic zone are connected by black lines with partial ruptures (orange stars) and slow earthquakes (yellow stars) in order of occurrence. $\mathbf{b}$ The earthquake catalog from the simulation with only brittle deformation along the megathrust segments. Events are connected by a blue line. c Slip deficit (black and blue for models with and without viscoelastic flow, respectively) at the center of the seismogenic zone (segment B). Earthquake recurrence time starts to be modulated by viscoelastic flow after several super-cycles (about 560 years). a-c share the same $x$-axis. $\mathbf{d}$ The enlarged view of earthquake cycles of the time period between 500 and 600 years in $\mathbf{c}$. e and $\mathbf{f}$ share the same $\mathrm{x}$-axis as $\mathbf{d}$. e Effect of viscoelastic flow on long-term slow-slip events. $\mathbf{f}$ Effect of asthenosphere flow on short-term slow-slip events. $\mathbf{g}$ Distribution of recurrence times for earthquakes with force larger than $10^{8} \mathrm{~N}$ (all ruptures) with (gray) our without (blue) coupling with viscoelastic flow. $\mathbf{h}$ Distribution of recurrence time of great earthquakes with force larger than $10^{10} \mathrm{~N}$ (only full ruptures) 
modulated by nearby ruptures, but the slow-slip cycle endures over multiple seismic cycles or super-cycles. Different types of ruptures, slow and fast, occur near the boundaries of the seismogenic zone, but full and partial ruptures still represent the dominant style of rupture in the forearc. The cycles are aperiodic, but the types of ruptures are pre-determined.

A first-order understanding of the down-dip segmentation of the seismic cycle at subduction zone benefits from integrating geological and theoretical insights. The variability of earthquake sizes results from the nonlinear dynamics of fault slip, favored by a short weakening distance and a large seismogenic zone. Megathrusts intersect the cold, brittle crust at low angle, providing a large area for great and giant ruptures, but also the conditions for complex earthquake cycles. This has important implications for understanding seismic hazards, because no temporal window of observation may capture a representative seismic cycle or super-cycle. The interactions between the seismogenic zone and the neighboring segments introduce dramatic changes in the seismic cycle and the mechanical system never converges to a limit cycle. In addition, viscoelastic flow in the asthenosphere produces a subtle modulation of the recurrence times and, in some case, rupture styles, on the megathrust.

The proposed mechanical model of the Nankai Trough highlights some important differences with other subduction zones. For example, the Cascadia subduction zone does not feature the type of long-term slow-slip events found in the Nankai. The structural layout of the Middle American trench differs crucially, with longterm and short-term slow-slip events taking place along a large-scale ramp-flat section of the megathrust. In the Japan trench, giant ruptures break all the way to the trench, a type of event that does not appear in the current simulations. The development of long-term slow-slip events in our model requires the presence of a wide metamorphic belt in the mantle wedge corner. Perhaps due to its temperature profile and degree of metamorphism, this region may be under-developed in Cascadia or along the Chilean trench.

The model does not explain the formation of tsunami earthquakes in some accretionary regions. Tsunami earthquakes may occur in a more sophisticated model that better resolves the internal stratification of the accretionary wedge (Leggett et al. 1985; Moore et al. 1990; Park et al. 2000; Kodaira et al. 2000; Takahashi et al. 2003; Ito et al. 2009), with different properties in the frontal prism, e.g., high-angle ramps, smectite and illite layers (Saffer and Marone 2003; den Hartog et al. 2012). The model does captures the unstable nature of the accretionary wedge, but many different rupture styles and types of seismic cycles can be obtained in an unstable domain, depending on the details of the parameters and where they fall in phase space. In addition, even with the same frictional parameters, the dynamics of two accretionary prisms may be grossly dissimilar, simply based on their geometry, i.e., width on the megathrust, dip angle of basal décollement, distance to the free surface (sediment thickness), and degree of internal deformation. Therefore, we expect different behaviors in a sediment-thick Lesser Antilles subduction zone and a sediment-starved northern Chile margin, for example. The fabric of the upper plate also varies greatly within the Nankai Trough, with a mega-splay fault bounding the accretionary prism from the forearc offshore the Kii Peninsula (Park et al. 2002), with many reverse faults occupying the entire outer wedge (Park et al. 2010; Kamei et al. 2012; Tsuji et al. 2014, 2015, 2017; Shiraishi et al. 2019). We therefore anticipate important along-strike variations with different rupture styles in the accretionary region even within the Nankai Trough.

\section{Conclusions}

The down-dip segmentation of rupture styles at subduction zones indicates a strong control from the thermomechanical structure and composition of the upper plate. At the Nankai Trough, the development of slow earthquakes, large earthquakes, and long-term and shortterm slow-slip events can be reconciled with a structural model that considers the intersection of the megathrust with the accretionary prism, the arc crust, a metamorphic belt, the mantle lid, and some important isotherms coinciding with the stability transition of granitic rocks and peridotite (Fig. 11). The geological structure provides the boundary and physical conditions for the unfolding of the seismic cycle. Using the integral method within a two-dimensional approximation, we simulate the seismic cycle in the viscoelastic medium of the lithosphereasthenosphere system. With a choice of parameters informed by the geological setting, laboratory experiments, and theoretical insights, we reproduce several key rupture styles with their structural setting, providing new insights into the coupled dynamics of slow and fast ruptures and distributed deformation at subduction zones.

Our model illustrates how the geological structure of the overriding plate controls the down-dip segmentation of ruptures styles, but also how the nonlinear behavior of fault dynamics and the interactions of various parts of the mechanical system induce additional complexity. For example, the recurrence time and magnitudes of earthquakes and slow-slip events exhibit great variability. The short-term slow-slip events can be accelerated for several years following a great earthquake, and the long-term slow slip can be suppressed for decades in the early stage 


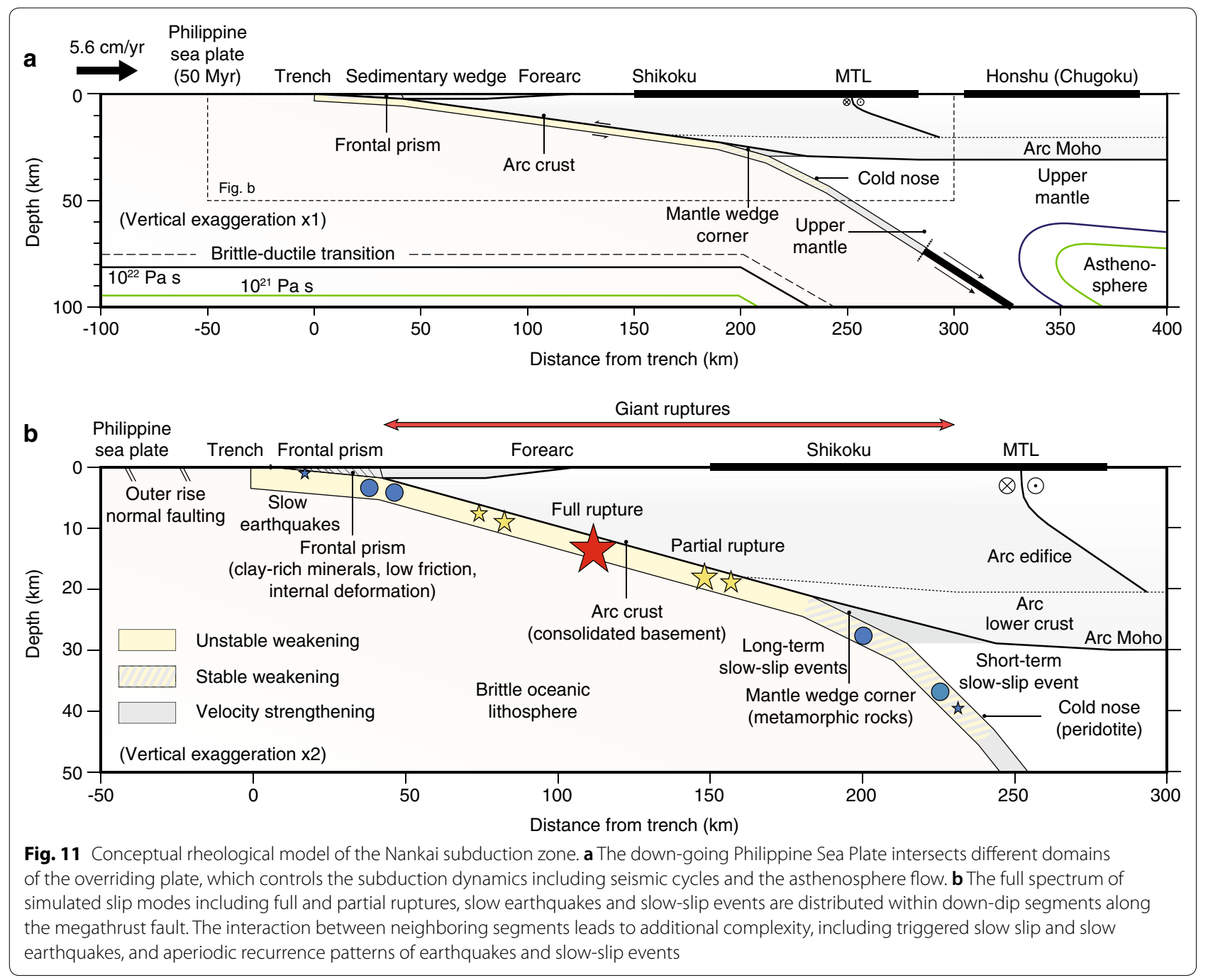

of a super-cycle. This suggests the possible sudden reactivation of slow slip after a long period of creep following a great earthquake. The propagation of creep waves in the shallowest segment reflects the instability of shallow slip and a potential for tsunami-genic ruptures.

Our modeling approach is well suited to simulate fault dynamics within a complex geological framework. Future work will expand the structural complexity. For example, coupling in-plane and anti-plane fault dynamics may be important to represent the oblique convergence at a plate boundary, which is partitioned into the megathrust and an along-arc strike-slip fault in many regions. Addition of splay faults, backthrusts, and normal faults may better represent the seismicity at subduction zones. Eventually, three-dimensional models will be required to capture along-strike segmentation and to produce more realistic simulations of seismological and geodetic data.

\section{Acknowledgements}

We thank Roland Bürgmann and an anonymous reviewer for their constructive comments.

\section{Authors' contributions}

All authors contributed to the design of the study and reviewed the manuscript. QS conducted the study. QS and SB wrote the manuscript. All authors read and approved the final manuscript.

\section{Funding}

This study was funded by the National Science Foundation under grant no. EAR-1848192.

\section{Availability of data and materials}

The code and input files used in the study are available upon request.

\section{Competing interests}

The authors declare that they have no competing interests.

\section{Author details}

${ }^{1}$ Earth Observatory of Singapore, Asian School of the Environment, Nanyang Technological University, Singapore, Singapore. ${ }^{2}$ Department of Earth Sciences, University of Southern California, Los Angeles, USA. ${ }^{3}$ Institute of Crustal 
Dynamics, China Earthquake Administration, Beijing, China. ${ }^{4}$ National Research Institute for Earth Science and Disaster Resilience, Tsukuba, Japan. ${ }^{5}$ International Institute of Seismology and Earthquake Engineering, Building Research Institute, Tsukuba, Japan.

Received: 3 October 2019 Accepted: 24 January 2020 Published online: 02 March 2020

\section{References}

Agard P, Yamato P, Jolivet L, Burov E (2009) Exhumation of oceanic blueschists and eclogites in subduction zones: timing and mechanisms. Earth Sci Rev 92(1-2):53-79

Agata R, Barbot SD, Fujita K, Hyodo M, linuma T, Nakata R, Ichimura T, Hori T (2019) Rapid mantle flow with power-law creep explains deformation after the 2011 tohoku mega-quake. Nat Commun 10(1):1385

Allison KL, Dunham EM (2018) Earthquake cycle simulations with rateand-state friction and power-law viscoelasticity. Tectonophysics 733:232-256

Ammon CJ, Kanamori H, Lay T, Velasco AA (2006) The 17, 2006 java tsunami earthquake. Geophys Res Lett 33(24)

Ando M (1975) Source mechanisms and tectonic significance of historical earthquakes along the Nankai trough, Japan. Tectonophysics 27(2):119-140

Andrews DJ (1976) Rupture propagation with finite stress in antiplane strain. J Geophys Res 81:3575-3582

Araki E et al (2017) Recurring and triggered slow-slip events near the trench at the Nankai trough subduction megathrust. Science 356(6343):1157-1160

Audet P, Bürgmann R (2014) Possible control of subduction zone slow-earthquake periodicity by silica enrichment. Nature 510(7505):389

Audet P, Schaeffer AJ (2018) Fluid pressure and shear zone development over the locked to slow slip region in Cascadia. Sci Adv 4(3):eaar2982

Barbot S (2018a) Deformation of a halfspace from anelastic strain confined in a tetrahedral volume. Bull Seismol Soc Am 108(5A):2687. https://doi. org/10.1785/0120180058

Barbot S (2018b) Asthenosphere flow modulated by megathrust earthquake cycles. Geophys Res Lett 45:6018-6031. https://doi.org/10.1029/2018G L078197

Barbot S (2019a) Modulation of fault strength during the seismic cycle by grain-size evolution around contact junctions. Tectonophysics 765:129-145

Barbot S (2019b) Slow-slip, slow earthquakes, period-two cycles, full and partial ruptures, and deterministic chaos in a single asperity fault. Tectonophysics 768:228171

Barbot S, Fialko Y (2010) A unified continuum representation of postseismic relaxation mechanisms: semi-analytic models of afterslip, poroelastic rebound and viscoelastic flow. Geophys J Int 182(3):1124-1140. https:// doi.org/10.1111/j.1365-246X.2010.04678.x

Barbot S, Fialko Y, Bock Y (2004) Postseismic deformation, due to the $M_{w}$ 6.0, (2004) Parkfield rarthquake: stress-driven creep on a fault with spatially variable rate-and-state friction parameters. J Geophys Res 114(B07405):2009. https://doi.org/10.1029/2008JB005748

Barbot S, Lapusta N, Avouac JP (2012) Under the hood of the earthquake machine: towards predictive modeling of the seismic cycle. Science 336(6082):707-710

Barbot S, Moore JD, Lambert V (2017) Displacement and stress associated with distributed anelastic deformation in a half-space. Bull Seismol Soc Am 107(2):821-855. https://doi.org/10.1785/0120160237

Bassett D, Sandwell DT, Fialko Y, Watts AB (2016) Upper-plate controls on coseismic slip in the 2011 magnitude 9.0 Tohoku-Oki earthquake. Nature 531(7592):92

Bedford J, Moreno M, Li S, Oncken O, Baez JC, Bevis M, Heidbach O, Lange D (2016) Separating rapid relocking, afterslip, and viscoelastic relaxation: an application of the postseismic straightening method to the maule 2010 CGPS. J Geophys Res 121(10):7618-7638

Bell R, Holden C, Power W, Wang X, Downes G (2014) Hikurangi margin tsunami earthquake generated by slow seismic rupture over a subducted seamount. Earth Planet Sci Lett 397:1-9
Beroza GC, Ide S (2011) Slow earthquakes and nonvolcanic tremor. Annu Rev Earth Planet Sci 39:271-96

Biemiller J, Lavier L (2017) Earthquake supercycles as part of a spectrum of normal fault slip styles. J Geophys Res 122(4):3221-3240

Bilek SL, Lay T (2002) Tsunami earthquakes possibly widespread manifestations of frictional conditional stability. Geophys Res Lett 29(14):4. https://doi. org/10.1029/2002GL015215

Bilek SL, Engdahl ER, DeShon HR, El Hariri M (2011) The 25 October 2010 Sumatra tsunami earthquake: slip in a slow patch. Geophys Res Lett 38(L14306):5

Bilham R (2015) Seismology: raising Kathmandu. Nat Geosci 8(8):582-584

Bizzarri A (2011) On the deterministic description of earthquakes. Rev Geophys. https://doi.org/10.1029/2011RG000,356

Blanpied ML, Lockner DA, Byerlee JD (1991) Fault stability inferred from granite sliding experiments at hydrothermal conditions. Geophys Res Lett 18(4):609-612

Blanpied ML, Lockner DA, Byerlee JD (1995) Frictional slip of granite at hydrothermal conditions. J Geophys Res 100(B7):13045-13064

Boettcher MS, Hirth G, Evans B (2007) Olivine friction at the base of oceanic seismogenic zones. J Geophys Res 112(B1). https://doi. org/10.1029/2006JB004301

Bollinger L, Klinger Y, Tapponnier P, Gaudemer Y, Tiwari D (2013) Estimating the return times of great Himalayan earthquakes in eastern Nepal: evidence from the Patu and Bardibas strands of the Main Frontal Thrust. Nat Geosci 6:71-76

Bruhat L, Barbot S, Avouac JP (2011) Evidence for postseismic deformation of the lower crust following the $2004 M_{w} 6.0$ Parkfield earthquake. J Geophys Res 116:10

Bürgmann R (2018) The geophysics, geology and mechanics of slow fault slip. Earth Planet Sci Lett 495:112-134

Burke K (2011) Plate tectonics, the wilson cycle, and mantle plumes: geodynamics from the top. Annu Rev Earth Planet Sci 39:1-29

Byrne T, Fisher D (1990) Evidence for a weak and overpressured decollement beneath sediment-dominated accretionary prisms. J Geophys Res Solid Earth 95(B6):9081-9097

Cattania C (2019) Complex earthquake sequences on simple faults. Geophys Res Lett. https://doi.org/10.1029/2019GL083628

Cattania C, Segall P (2018) Crack models of repeating earthquakes predict observed moment-recurrence scaling. J Geophys Res. https://doi. org/10.1029/2018JB016056

Chen T, Lapusta N (2009) Scaling of small repeating earthquakes explained by interaction of seismic and aseismic slip in a rate and state fault model. J Geophys Res 114(B01311):12

Chester FM (1989) Dynamic recrystallization in semi-brittle faults. J Struct Geol 11(7):847-858

Chester FM (1994) Effects of temperature on friction: constitutive equations and experiments with fault gouge. J Geophys Res 99(B4):7247-7261

Chester FM, Higgs N (1992) Multimechanism friction constitutive model for ultrafine quartz gouge at hypocentral conditions. J Geophys Res 97(B2):1859-1870

Chinnery M (1963) The stress changes that accompany strike-slip faulting. Bull Seismol Soc Am 53(5):921-932

Chiu Y (1978) On the stress field and surface deformation in a half space with a cuboidal zone in which initial strains are uniform. J Appl Mech 45(2):302-306

Chlieh M et al (2007) Coseismic slip and afterslip of the great $M_{\mathrm{w}} 9.15$ SumatraAndaman earthquake of 2004. Bull Seismol Soc Am 97(1A):S152-S173. https://doi.org/10.1785/0120050631

Chopra PN (1997) High-temperature transient creep in olivine rocks. Tectonophysics 279(104):93-111

Contreras-Reyes E, Carrizo D (2011) Control of high oceanic features and subduction channel on earthquake ruptures along the Chile-Peru subduction zone. Phys Earth Planet Inter 186(1-2):49-58

Contreras-Reyes E, Flueh ER, Grevemeyer I (2010) Tectonic control on sediment accretion and subduction off south central Chile: Implications for coseismic rupture processes of the 1960 and 2010 megathrust earthquakes. Tectonics 29(6). https://doi.org/10.1029/2010TC002734

Cruz-Atienza VM, Villafuerte C, Bhat HS (2018) Rapid tremor migration and pore-pressure waves in subduction zones. Nat Commun 9(1):2900

Cubas N, Avouac J-P, Leroy YM, Pons A (2013) Low friction along the high slip patch of the $2011 M_{w}$ 9.0 Tohoku-Oki earthquake required from 
the wedge structure and extensional splay faults. Geophys Res Lett 40(16):4231-4237

den Hartog SAM, Spiers CJ (2014) A microphysical model for fault gouge friction applied to subduction megathrusts. JGR 119(2):1510-1529

Dieterich JH (1978) Time-dependent friction and the mechanics of stick-slip. Pure Appl Geophys 116(4-5):790-806

Dieterich JH (1979) Modeling of rock friction 1. Experimental results and constitutive equations. J Geophys Res 84(B5):2161-2168

Dimanov A, Dresen G (2005) Rheology of synthetic anorthite-diopside aggregates: implications for ductile shear zones. J Geophys Res 110 (B7). https ://doi.org/10.1029/2004JB003431

Dixon TH, Jiang Y, Malservisi R, McCaffrey R, Voss N, Protti M, Gonzalez V (2014) Earthquake and tsunami forecasts: relation of slow slip events to subsequent earthquake rupture. Proc Natl Acad Sci 111(48):17039-17044

Erickson BA, Dunham EM, Khosravifar A (2017) A finite difference method for off-fault plasticity throughout the earthquake cycle. J Mech Phys Solids 109:50-77

Erickson B et al (2020) The community code verification exercise for simulating sequences of earthquakes and aseismic slip (seas). Seismol Res Lett. https://doi.org/10.31223/osf.io/2dmp5 (in press)

Faivre G (1969) Deformations de coherence d'un precipite quadratique. Phys Stat Solidi (b) 35(1):249-259

Feng L, Barbot S, Hill EM, Hermawan I, Banerjee P, Natawidjaja DH (2016) Footprints of past earthquakes revealed in the afterslip of the $2010 \mathrm{M}_{\mathrm{w}} 7.8$ mentawai tsunami earthquake. Geophys Res Lett 43(18):9518-9526

Feng W et al (2017) Source characteristics of the $2015 M_{w} 7.8$ gorkha (nepal) earthquake and its $M_{w w} 7.2$ aftershock from space geodesy. Tectonophysics 712:747-758

Frank WB, Shapiro NM, Husker AL, Kostoglodov V, Bhat HS, Campillo M (2015) Along-fault pore-pressure evolution during a slow-slip event in Guerrero, Mexico. Earth Planet Sci Lett 413:135-143

Freed AM, Bürgmann R (2004) Evidence of power-law flow in the Mojave desert mantle. Nature 430:548-551

Freed AM, Herring T, Bürgmann R (2010) Steady-state laboratory flow laws alone fail to explain postseismic observations. Earth Planet Sci Lett 300:1-10

Fukuyama E (2007) Fault structure, stress, friction and rupture dynamics of earthquakes. In: Advances in earth science: from earthquakes to global warming, pp 109-131, World Scientific

Gao X, Wang K (2017) Rheological separation of the megathrust seismogenic zone and episodic tremor and slip. Nature 543(7645):416-419

Geersen J (2019) Sediment-starved trenches and rough subducting plates are conducive to tsunami earthquakes. Tectonophysics 762:28-44

Gimbutas Z, Greengard L, Barall M, Tullis TE (2012) On the calculation of displacement, stress, and strain induced by triangular dislocations. Bull Seismol Soc Am 102(6):2776-2780

Gleason GC, Tullis J (1995) A flow law for dislocation creep of quartz aggregates determined with the molten salt cell. Tectonophysics 247(1-4):1-23

Gomberg JC, Group BW (2010) Slow-slip phenomena in Cascadia from 2007 and beyond: a review. Bulletin 122(7--8):963-978

Goswami A, Barbot S (2018) Slow-slip events in semi-brittle serpentinite fault zones. Sci Rep 8(1):6181

Hayes GP (2017) The finite, kinematic rupture properties of great-sized earthquakes since 1990. Earth Planet Sci Lett 468:94-100

Hayes GP, Wald DJ, Johnson RL (2012) Slab1.0: a three-dimensional model of global subduction zone geometries. J Geophys Res. https://doi. org/10.1029/2011JB008524

Hayes GP, Moore GL, Portner DE, Hearne M, Flamme H, Furtney M, Smoczyk GM (2018) Slab2, a comprehensive subduction zone geometry model. Science 362(6410):58-61

Herrendörfer R, Van Dinther Y, Gerya T, Dalguer LA (2015) Earthquake supercycle in subduction zones controlled by the width of the seismogenic zone. Nat Geosci 8(6):471-474

Hetland EA, Hager BH (2005) Postseismic and interseismic displacements near a strike-slip fault: a two-dimensional theory for general linear viscoelastic rheologies. J Geophys Res 110(B10):401

Heuret A, Lallemand S, Funiciello F, Piromallo C, Faccenna C (2011) Physical characteristics of subduction interface type seismogenic zones revisited. Geochem Geophys Geosyst 12(1). https://doi.org/10.1029/2010G C003230
Hilairet N, Reynard B, Wang Y, Daniel I, Merkel S, Nishiyama N, Petitgirard S (2007) High-pressure creep of serpentine, interseismic deformation, and initiation of subduction. Science 318(5858):1910-1913

Hirahara K (2002) Interplate earthquake fault slip during periodic earthquake cycles in a viscoelastic medium at a subduction zone. Pure Appl Geophys 159(10):2201-2220

Hirose H, Obara K (2005) Repeating short-and long-term slow slip events with deep tremor activity around the bungo channel region, Southwest Japan. Earth Planet Space 57(10):961-972. https://doi.org/10.1186/ BF03351875

Hirose H, Obara K (2006) Short-term slow slip and correlated tremor episodes in the Tokai region, central Japan. Geophys Res Lett 33(17). https://doi. org/10.1029/2006GL026579

Hirose H, Hirahara K, Kimata F, Fujii N, Miyazaki S (1999) A slow thrust slip event following the two 1996 Hyuganada earthquakes beneath the bungo channel, Southwest Japan. Geophys Res Lett 26(21):3237-3240

Hirth G, Kohlstedt DL (2003) Rheology of the upper mantle and the mantle wedge: a view from the experimentalists. In: Inside the subduction factory, Geophys Monogr vol. 138, edited by J. Eiler, pp 83-105, Am. Geophys. Soc., Washington, D. C

Hirose F, Nakajima J, Hasegawa A (2008) Three-dimensional seismic velocity structure and configuration of the Philippine Sea slab in southwestern Japan estimated by double difference tomography. JGR 113(B9)

Hirth G, Tullis J (1992) Dislocation creep regimes in quartz aggregates. J Struct Geol 14(2):145-159

Hoechner A, Sobolev SV, Einarsson I, Wang R (2011) Investigation on afterslip and steady state and transient rheology based on postseismic deformation and geoid change caused by the Sumatra 2004 earthquake, Geochem Geophys Geosyst 12(7). https://doi.org/10.1029/2010GC0034 50

Holtzman B, Chrysochoos A, Daridon L (2018) A thermomechanical framework for analysis of microstructural evolution: application to olivine rocks at high temperature. J Geophys Res 123(10):8474-8507

Hori T (2006) Mechanisms of separation of rupture area and variation in time interval and size of great earthquakes along the Nankai trough, Southwest Japan. Earth Simul 5:8-19

Hori T, Kato N, Hirahara K, Baba T, Kaneda Y (2004) A numerical simulation of earthquake cycles along the Nankai trough in Southwest Japan: lateral variation in frictional property due to the slab geometry controls the nucleation position. Earth Planet Sci Lett 228(3-4):215-226

Hsu Y-J, Simons M, Avouac J-P, Galetzka J, Sieh K, Chlieh M, Natawidjaja D, Prawirodirdjo L, Bock Y (2006) Friction afterslip following the 2005 NiasSimeulue earthquake Sumatra. Science 312:1921-1926

Hu Y, Wang K, He J, Klotz J, Khazaradze G (2004) Three-dimensionalviscoelastic finite element model for postseismic deformation of thegreat 1960 Chile earthquake. J Geophys Res 109(B12). https://doi. org/10.1029/2004JB003163

Hu Y, Bürgmann R, Uchida N, Banerjee P, Freymueller JT (2016) Stress-driven relaxation of heterogeneous upper mantle and time-dependent afterslip following the 2011 Tohoku earthquake. J Geophys Res 121(1):385-411

Hubbard J, Barbot S, Hill EM, Tapponnier P (2015) Coseismic slip on shallow décollement megathrusts: implications for seismic and tsunami hazard. Earth Sci Rev 141:45-55

Hubbard J, Almeida R, Foster A, Sapkota SN, Bürgi P, Tapponnier P (2016) Structural segmentation controlled the $2015 M_{w} 7.8$ Gorkha earthquake rupture in Nepal. Geology 44(8):639-642

Hyndman RD, Yamano M, Oleskevich DA (1997) The seismogenic zone of subduction thrust faults. Island Arc 6(3):244-260

Hyodo M, Hori T (2013) Re-examination of possible great interplate earthquake scenarios in the Nankai trough, Southwest Japan, based on recent findings and numerical simulations. Tectonophysics 600:175-186

Ikari MJ (2019) Laboratory slow slip events in natural geologic materials. Geophys J Int 218:354-387

Ikari MJ, Kopf AJ (2017) Seismic potential of weak, near-surface faults revealed at plate tectonic slip rates. Sci Adv 3(11):e1701269

Ishii M, Shearer PM, Houston H, Vidale JE (2005) Extent, duration and speed of the 2004 Sumatra-Andaman earthquake imaged by the hi-net array. Nature 435(7044):933 
Ito Y, Obara K, Shiomi K, Sekine S, Hirose H (2007) Slow earthquakes coincident with episodic tremors and slow slip events. Science 315:503-506

Ito T, Kojima Y, Kodaira S, Sato H, Kaneda Y, Iwasaki T, Kurashimo E, Tsumura N, Fujiwara A, Miyauchi T et al (2009) Crustal structure of southwest Japan, revealed by the integrated seismic experiment Southwest Japan 2002 TECTON 472(1-4):124-134

Jiang Y, Wdowinski S, Dixon TH, Hackl M, Protti M, Gonzalez V (2012) Slow slip events in costa Rica detected by continuous GPS observations, 20022011. Geochem Geophys Geosyst 13(4). https://doi.org/10.1029/2012G C004058

Johnson JM, Satake K (1997) Estimation of seismic moment and slip distribution of the April 1, 1946, Aleutian Tsunami earthquake. J Geophys Res 102(B6):11765-11774

Johnson KM, Bürgmann R, Freymueller JT (2009) Coupled afterslip and viscoelastic flow following the 2002 Denali Fault, Alaska earthquake. Geophys J Int 176(3):670-682

Kamei R, Pratt RG, Tsuji T (2012) Waveform tomography imaging of a megasplay fault system in the seismogenic Nankai subduction zone. EPSL 317:343-353. https://doi.org/10.1186/s40623-020-1145-0

Kanamori H (1972) Mechanism of tsunami earthquakes. Phys Earth Planet Inter 6(5):346-359

Kanamori H, Kikuchi M (1993) The 1992 nicaragua earthquake: a slow tsunami earthquake associated with subducted sediments. Nature 361(6414):714

Kanamori H, Rivera L, Lee WHK (2010) Historical seismograms for unraveling a mysterious earthquake: The 1907 Sumatra earthquake. Geophys J Int 183:358-374

Kaneko Y, Avouac J-P, Lapusta N (2010) Towards inferring earthquake patterns from geodetic observations of interseismic coupling. Nat Geosci 3:363-369

Kano M, Kato A, Obara K (2019) Episodic tremor and slip silently invades strongly locked megathrust in the Nankai trough. Sci Rep 9(1):9270

Karato S-I (2008) Deformation of earth materials: an introduction to the rheology of solid earth. Cambridge Univ. Press, Cambridge, U. K.

Karato S-I, Jung H (2003) Effects of pressure on high-temperature dislocation creep in olivine. Philos Mag 83(3):401-414

Karato S-I, Paterson MS, Fitzgerald JD (1986) Rheology of synthetic olivine aggregates_influence of grain size and water. J Geophys Res 91:81518176. https://doi.org/10.1029/JB091iB08p08151

Katayama I, Iwata M, Okazaki K, Hirauchi KI (2013) Slow earthquakes associated with fault healing on a serpentinized plate interface. Sci Rep 3:1784

Kato N (2003) Repeating slip events at a circular asperity: numerical simulation with a rate-and state-dependent friction law. Bull Earthq Res Inst Univ Tokyo 78:151-166

Kato N (2012) Dependence of earthquake stress drop on critical slip-weakening distance. J Geophys Res 117(B1):705-708. https://doi.org/10.1126/ science. 1215141

Kato N, Tullis TE (2001) A composite rate- and state-dependent law for rock friction. Geophys Res Lett 28:1103-1106

Kawakatsu H, Watada S (2007) Seismic evidence for deep-water transportation in the mantle. Science 316(5830):1468-1471

Kawamura T, Onishi M, Kurashimo E, Ikawa T, Ito T (2003) Deep seismic reflection experiment using a dense receiver and sparse shot technique for imaging the deep structure of the Median Tectonic Line (MTL) in east Shikoku, Japan. EPS 55(9):549-557

Kilgore BD, Blanpied ML, Dieterich JH (1993) Velocity dependent friction of granite over a wide range of conditions. Geophys Res Lett 20(10):903-906

King D, Marone C (2012) Frictional properties of olivine at high temperature with applications to the strength and dynamics of the oceanic lithosphere. J Geophys Res Solid Earth 117(B12). https://doi. org/10.1029/2012JB009511

Klein E, Fleitout L, Vigny C, Garaud J (2016) Afterslip and viscoelastic relaxation model inferred from the large-scale post-seismic deformation following the $2010 \mathrm{~m}$ w 8.8 maule earthquake (Chile). Geophys J Int 205(3):1455-1472

Kobayashi A (2014) A long-term slow slip event from 1996 to 1997 in the Kii channel, Japan. Earth Planet Space 66(1):9. https://doi. org/10.1186/1880-5981-66-9
Kodaira S, Takahashi N, Park J-O, Mochizuki K, Shinohara M, Kimura S (2000) Western Nankai Trough seismogenic zone: Results from a wide-angle ocean bottom seismic survey. JGR 105(B3):5887-5905

Kodaira S, lidaka T, Kato A, Park J-O, Iwasaki T, Kaneda Y (2004) High pore fluid pressure may cause silent slip in the Nankai trough. Science 304(5675):1295-1298

Kodaira S, Hori T, Ito A, Miura S, Fujie G, Park J-O, Baba T, Sakaguchi H, Kaneda $Y$ (2006) A cause of rupture segmentation and synchronization in the Nankai trough revealed by seismic imaging and numerical simulation. J Geophys Res 111 (B9). https://doi.org/10.1029/2005JB004030

Konca AO, Hjorleifsdottir V, Song A, Avouac J-P, Helmberger DV, Ji C, Sieh K, Briggs R, Meltzner A (2007) Rupture kinematics of the 2005, $M_{w} 8.6$, Nias-Simeulue earthquake from the joint inversion of seismic and geodetic data. Bull Seismol Soc Am 97(1A):S307-S322

Kozdon JE, Dunham EM (2013) Rupture to the trench: dynamic rupture simulations of the 11 March 2011 tohoku earthquake. Bull Seismol Soc Am 103(2B):1275-1289

Kumagai H (1996) Time sequence and the recurrence models for large earthquakes along the Nankai trough revisited. Geophys Res Lett 23(10):1139-1142

Kuvshinov BN (2008) Elastic and piezoelectric fields due to polyhedral inclusions. Int J Solids Struct 45(5):1352-1384

Lambert V, Barbot S (2016) Contribution of viscoelastic flow in earthquake cycles within the lithosphere-asthenosphere system. Geophys Res Lett 43(19):142-154

Lapusta N, Rice JR (2003) Nucleation and early seismic propagation of small and large events in a crustal earthquake model. J Geophys Res 108(B4):2205

Lay T, Ammon CJ, Kanamori H, Yamazaki Y, Cheung KF, Hutko AR (2011) The 25 October 2010 Mentawai tsunami earthquake $\left(M_{w} 7.8\right)$ and the tsunami hazard presented by shallow megathrust ruptures. Geophys Res Lett 38(L06302):5

Lay T, Kanamori H, Ammon CJ, Koper KD, Hutko AR, Ye L, Yue H, Rushing TM (2012) Depth-varying rupture properties of subduction zone megathrust faults. J Geophys Res 117(B04311):21. https://doi. org/10.1029/2011JB009133

Leeman J, Saffer D, Scuderi M, Marone C (2016) Laboratory observations of slow earthquakes and the spectrum of tectonic fault slip modes. Nat Commun 7(11):104

Leggett J, Aoki Y, Toba T (1985) Transition from frontal accretion to underplating in a part of the Nankai Trough accretionary complex off Shikoku (SW Japan) and extensional features on the lower trench slope. Mar Pet Geol 2(2):131-141

Li D, Liu Y (2016) Spatiotemporal evolution of slow slip events in a nonplanar fault model for northern cascadi subduction zone. J Geophys Res 121(9):6828-6845

Li D, Liu Y (2017) Modeling slow-slip segmentation in Cascadia subduction zone constrained by tremor locations and gravity anomalies. J Geophys Res 122(4):3138-3157

Li S, Moreno M, Bedford J, Rosenau M, Heidbach O, Melnick D, Oncken O (2017) Postseismic uplift of the andes following the 2010 maule earthquake: implications for mantle rheology. Geophys Res Lett 44(4):1768-1776

Li S, Wang K, Wang Y, Jiang Y, Dosso SE (2018) Geodetically inferred locking state of the Cascadia megathrust based on a viscoelastic earth model. J Geophys Res 123(9):8056-8072

Lin Y-NN et al (2013) Coseismic and postseismic slip associated with the 2010 Maule earthquake, Chile: characterizing the Arauco peninsula barrier effect. J Geophys Res Solid Earth 118(6):3142-3159

Linker MH, Dieterich JH (1992) Effects of variable normal stress on rock friction: observations and constitutive relations. J Geophys Res 97:4923-4940

Liu Y, Rice JR (2005) Aseismic slip transients emerge spontaneously in threedimensional rate and state modeling of subduction earthquake sequences. J Geophys Res. https://doi.org/10.1029/2004JB003424

Liu Y, Rubin AM (2010) Role of fault gouge dilatancy on aseismic deformation transients. J Geophys Res. https://doi.org/10.1029/2010JB007.522

Lorenzo-Martín F, Roth F, Wang R (2006) Inversion for rheological parameters from post-seismic surface deformation associated with the 1960 valdivia earthquake, Chile. Geophys J Int 164(1):75-87

Lui SK, Lapusta N (2016) Repeating microearthquake sequences interact predominantly through postseismic slip. Nat Commun 7(13):020 
Lyu Z, Rivière J, Yang Q, Marone C (2019) On the mechanics of granular shear: the effect of normal stress and layer thickness on stick-slip properties. Tectonophysics 763:86-99

Maeda T, Obara K (2009) Spatiotemporal distribution of seismic energy radiation from low-frequency tremor in western shikoku, Japan. J Geophys Res Solid Earth 114(B10). https://doi.org/10.1029/2008JB006043

Marone C, Kilgore B (1993) Scaling of the critical slip distance for seismic faulting with shear strain in fault zones. Nature 362:618-620

Marone C, Raleigh BC, Scholz CH (1990) Frictional behavior and constitutive modeling of simulated fault gouge. J Geophys Res 95(B5):7007-7026

Maruyama T (1964) Statical elastic dislocations in an infinite and semi-infinite medium. Bull Earthq Res Inst 42:289-368

Masuti S, Barbot S, Karato S, Feng L, Banerjee P (2016) Upper mantle water stratification inferred from the $2012 M_{\mathrm{w}} 8.6$ Indian Ocean earthquake. Nature 538:373-377. https://doi.org/10.1038/nature19783

Masuti S, Karato S-I, Girard J, Barbot SD (2019) Anisotropic high-temperature creep in hydrous olivine single crystals and its geodynamic implications. Phys Earth Planet Inter 290:1-9

Matsuzawa T, Hirose H, Shibazaki B, Obara K (2010) Modeling short- and long-term slow slip events in the seismic cycles of large subduction earthquakes. J Geophys Res. https://doi.org/10.1029/2010JB007566

Matsuzawa T, Shibazaki B, Obara K, Hirose H (2013) Comprehensive model of short-and long-term slow slip events in the Shikoku region of Japan, incorporating a realistic plate configuration. Geophys Res Lett 40(19):5125-5130

Mclaskey GC, Yamashita F (2017) Slow and fast ruptures on a laboratory fault controlled by loading characteristics. J Geophys Res 122(5):3719-3738

Mei S, Kohlstedt D (2000) Influence of water on plastic deformation of olivine aggregates: 1. Diffusion creep regime. J Geophys Res 105(B9):21457-21469

Meier M-A, Ampuero J, Heaton TH (2017) The hidden simplicity of subduction megathrust earthquakes. Science 357(6357):1277-1281

Mencin D et al (2016) Himalayan strain reservoir inferred from limited afterslip following the Gorkha earthquake. Nat Geosci 9:533-577

Metois M, Vigny C, Socquet A (2016) Interseismic coupling, megathrust earthquakes and seismic swarms along the chilean subduction zone (38-18 s). Pure Appl Geophys 173(5):1431-1449

Michel S, Avouac J-P, Lapusta N, Jiang J (2017) Pulse-like partial ruptures and high-frequency radiation at creeping-locked transition during megathrust earthquakes. Geophys Res Lett 44(16):8345-8351

Mitchell E, Fialko Y, Brown K (2013) Temperature dependence of frictional healing of westerly granite: experimental observations and numerical simulations. Geochem Geophys Geosyst 14(3):567-582

Mitchell E, Fialko Y, Brown K (2016) Velocity-weakening behavior of westerly granite at temperature up to $600^{\circ} \mathrm{C}$. J Geophys Res 121(9):6932-6946

Moore GF, Shipley T, Stoffa P, Karig D, Taira A, Kuramoto S, Tokuyama H, Suyehiro K (1990) Structure of the Nankai trough accretionary zone from multichannel seismic reflection data. J Geophys Res 95(B6):8753-8765

Moreno M (2012) Toward understanding tectonic control on the $M_{w} 8.82010$ Maule Chile earthquake. Earth Planet Sci Lett 321:155-165

Muto J, Moore JDP, Barbot S, linuma T, Ohta Y, Horiuchi S, Iwamori H (2011) Persistent deep afterslip driven by nonlinear transient mantle flow after the Tohoku earthquake. Sci Adv. https://doi.org/10.1126/sciadv.aaw1164

Nagata K, Nakatani M, Yoshida S (2012) A revised rate-and state-dependent friction law obtained by constraining constitutive and evolution laws separately with laboratory data. J Geophys Res 117(B2). https://doi. org/10.1029/2011JB008818

Naif S, Key K, Constable S, Evans R (2013) Melt-rich channel observed at the lithosphere-asthenosphere boundary. Nature 495(7441):356

Naif S, Key K, Constable S, Evans RL (2015) Water-rich bending faults at the Middle America trench. Geochem Geophys Geosyst 16(8):2582-2597

Nakajima J, Hasegawa A (2007) Subduction of the Philippine Sea plate beneath southwestern Japan: Slab geometry and its relationship to arc magmatism. JGR 112(B8). https://doi.org/10.1186/s40623-020-1145-0

Nakajima J, Uchida N (2018) Repeated drainage from megathrusts during episodic slow slip. Nat Geosci 11(5):351

Nakano M, Hori T, Araki E, Kodaira S, Ide S (2018) Shallow very-low-frequency earthquakes accompany slow slip events in the nankai subduction zone. Nat Commun 9(1):984

Nakata R, Hori T, Hyodo M, Ariyoshi K (2016) Possible scenarios for occurrence of $\mathrm{m} \sim 7$ interplate earthquakes prior to and following the
2011 Tohoku-Oki earthquake based on numerical simulation. Sci Rep 6(25):704

Nakatani M (2001) Conceptual and physical clarification of rate and state friction: frictional sliding as a thermally activated rheology. J Geophys Res 106(B7):13347-13380

Newman AV, Hayes G, Wei Y, Convers J (2011) The 25 October 2010 Mentawai tsunami earthquake, from real-time discriminants, finite-fault rupture, and tsunami excitation. Geophys Res Lett 38(L05302):7

Nikkhoo M, Walter TR (2015) Triangular dislocation: an analytical, artefact-free solution. Geophys I Int 201(2):1117-1139

Nishikawa T, Matsuzawa T, Ohta K, Uchida N, Nishimura T, Ide S (2019) The slow earthquake spectrum in the Japan trench illuminated by the s-net seafloor observatories. Science 365(6455):808-813

Nocquet J-M et al (2017) Supercycle at the ecuadorian subduction zone revealed after the 2016 Pedernales earthquake. Nat Geosci 10(2):145

Noda H, Lapusta N (2010) Three-dimensional earthquake sequence simulations with evolving temperature and pore pressure due to shear heating: Effect of heterogeneous hydraulic diffusivity. J Geophys Res 115(B12314):24

Noda A, Takahama T, Kawasato T, Matsu'ura M (2018) Interpretation of offshore crustal movements following the 2011 Tohoku-Oki earthquake by the combined effect of afterslip and viscoelastic stress relaxation. Pure Appl Geophys 175(2):559-572

Nozaki H, Taya M (2001) Elastic fields in a polyhedral inclusion with uniform eigenstrains and related problems. J Appl Mech 68(3):441-452

Nur A, Mavko G (1974) Postseismic viscoelastic rebound. Science 183:204-206

Obara K (2002) Nonvolcanic deep tremor associated with subduction in Southwest Japan. Science 296(5573):1679-1681

Obara K, Kato A (2016) Connecting slow earthquakes to huge earthquakes. Science 353(6296):253-257

Obara K, Hirose H, Yamamizu F, Kasahara K (2004) Episodic slow slip events accompanied by non-volcanic tremors in Southwest Japan subduction zone. Geophys Res Lett 31(23). https://doi.org/10.1029/2004GL020848

Obara K, Tanaka S, Maeda T, Matsuzawa T (2010) Depth-dependent activity of non-volcanic tremor in Southwest Japan. Geophys Res Lett 37(13). https://doi.org/10.1029/2010GL043679

Okada Y (1992) Internal deformation due to shear and tensile faults in a halfspace. Bull Seismol Soc Am 82:1018-1040

Okazaki K, Katayama I (2015) Slow stick slip of antigorite serpentinite under hydrothermal conditions as a possible mechanism for slow earthquakes. Geophys Res Lett 42(4):1099-1104

Okazaki K, Katayama I, Takahashi M (2013) Effect of pore fluid pressure on the frictional strength of antigorite serpentinite. Tectonophysics 583:49-53

Oleskevich D, Hyndman R, Wang K (1999) The updip and downdip limits to great subduction earthquakes: Thermal and structural models of Cascadia, south Alaska, sw Japan, and Chile. J Geophys Res 104(B7):14965-14991

Ong M, Qing Su, Barbot S, Hubbard J (2019) Physics-based scenario of earthquake cycles on the Ventura Thrust system, California: the effect of variable friction and fault geometry. Pure Appl Geophys. https://doi. org/10.1007/s00024-019-02111-9

Pacheco JF, Sykes LR, Scholz CH (1993) Nature of seismic coupling along simple plate boundaries of the subduction type. J Geophys Res 98(B8):14133-14159

Park J-O, Tsuru T, Kodaira S, Nakanishi A, Miura S, Kaneda Y, Kono Y, Takahashi N (2000) Out-of-sequence thrust faults developed in the coseismic slip zone of the 1946 Nankai earthquake ( $M w=8.2$ ) off Shikoku southwest, Japan. GRL 27(7):1033-1036

Park J-O, Tsuru T, Kodaira S, Cummins PR, Kaneda Y (2002) Splay fault branching along the Nankai subduction zone. Am Assoc Adv Sci 297(5584):11571160. https://doi.org/10.1126/science.1074111

Park J-O, Fujie G, Wijerathne L, Hori T, Kodaira S, Fukao Y, Moore GF, Bangs NL, Kuramoto S, Taira A (2010) A low-velocity zone with weak reflectivity along the Nankai subduction zone. Geology 38(3):283-286

Patton JR et al (2015) A 6600 year earthquake history in the region of the 2004 Sumatra-Andaman subduction zone earthquake. Geosphere 11(6):2067-2129

Payero JS, Kostoglodov V, Shapiro N, Mikumo T, Iglesias A, Pérez-Campos $X$, Clayton RW (2008) Nonvolcanic tremor observed in the Mexican subduction zone. Geophys Res Lett 35(7) 
Pelayo AM, Wiens DA (1990) The November 20, 1960 Peru tsunami earthquake: source mechanism of a slow event. Geophys Res Lett 17(6):661-664

Pelayo AM, Wiens DA (1992) Tsunami earthquakes: slow thrust-faulting events in the accretionary wedge. J Geophys Res 97(B11):15321-15337

Peng Z, Gomberg J (2010) An integrated perspective of the continuum between earthquakes and slow-slip phenomena. Nat Geosci 3(9):599

Perfettini H, Avouac J-P (1992) Modeling afterslip and aftershocks following the Landers earthquake. J Geophys Res 112(B07409):2007

Perfettini H, Avouac J-P (2004) Postseismic relaxation driven by brittle creep: a possible mechanism to reconcile geodetic measurements and the decay rate of aftershocks, application to the Chi-Chi earthquake, Taiwan. J Geophys Res 109(B02304). https://doi.org/10.1029/2003J B002488

Philibosian B et al (2017) Earthquake supercycles on the Mentawai segment of the sunda megathrust in the seventeenth century and earlier. J Geophys Res 122(1):642-676

Plafker G (1965) Tectonic deformation associated with the 1964 Alaska earthquake: the earthquake of 27 March 1964 resulted in observable crustal deformation of unprecedented areal extent. Science 148(3678):1675-1687

Platt JP, Xia H, Schmidt WM (2018) Rheology and stress in subduction zones around the aseismic/seismic transition. Prog Earth Planet Sci 5(1):24

Pollitz F, Banerjee P, Grijalva K, Nagarajan B, Bürgmann R (2008) Effect of 3-D viscoelastic structure on post-seismic relaxation from the $2004 \mathrm{~m}=9.2$ Sumatra earthquake. Geophys J Int 173(1):189-204

Press WH, Teukolsky SA, Vetterling WT (1992) Numerical recipes in C: the art of scientific computing, 2nd edn. Cambridge Univ. Press, New York, p 994

Qiu Q et al (2016) The mechanism of partial rupture of a locked megathrust: the role of fault morphology. Geology 44(10):875-878

Qiu Q, Moore JDP, Barbot S, Feng L, Hill E (2018) Transient viscosity in the Sumatran mantle wedge from a decade of geodetic observations. Nat Commun. https://doi.org/10.1038/s41467-018-03298-6

Ranero CR, Morgan JP, McIntosh K, Reichert C (2003) Bending-related faulting and mantle serpentinization at the Middle America trench. Nature 425(6956):367

Rice JR, Ben-Zion Y (1996) Slip complexity in earthquake fault models. Proc Natl Acad Sci 93(9):3811-3818

Rice JR, Ruina AL (1983) Stability of steady frictional slipping. J Appl Mech 50:343-349

Rice JR, Tse ST (1986) Dynamic motion of a single degree of freedom system following a rate and state dependent friction law. J Geophys Res 91(B1):521-530

Rice JR, Lapusta N, Ranjith K (2001) Rate and state dependent friction and the stability of sliding between elastically deformable solids. J Mech Phys Solids 49:1865-1898

Rikitake T (1976) Recurrence of great earthquakes at subduction zones. Tectonophysics 35(4):335-362

Rogers G, Dragert H (2003) Episodic tremor and slip on the Cascadia subduction zone: the chatter of silent slip. J Geophys Res. https://doi. org/10.1126/science.1084783

Rolandone F et al (2018) Areas prone to slow slip events impede earthquake rupture propagation and promote afterslip. Sci Adv 4(1):eaao6596

Rollins JC, Barbot S, Avouac J-P (2015) Postseismic Deformation Following the 2010 M=7.2 El Mayor-Cucapah Earthquake: Observations, Kinematic Inversions, and Dynamic. Models. Pure Appl Geophys 172(5):1305-1358

Rousset B, Barbot S, Avouac JP, Hsu Y-J (2012) Postseismic deformation following the 1999 Chi-Chi Earthquake, Taiwan: implication for lower-crust rheology. J Geophys Res 117(B12405):16

$J$ Geophys Res (2008) Episodic slow slip events and rate-and-state friction. https://doi.org/10.1029/2008JB005642

Rubin CM, Horton BP, Sieh K, Pilarczyk JE, Daly P, Ismail N, Parnell AC (2017) Highly variable recurrence of tsunamis in the 7,400 years before the 2004 Indian Ocean tsunami. Nat Commun 8(16):019

Ruina A (1983) Slip instability and state variable friction laws. J Geophys Res 88:10359-10370

Rüpke LH, Morgan JP, Hort M, Connolly JA (2004) Serpentine and the subduction zone water cycle. Earth Planet Sci Lett 223(1-2):17-34

Rybacki E, Dresen G (2000) Dislocation and diffusion creep of synthetic anorthite aggregates. J Geophys Res 105(B11):26017-26036

Saffer DM, Marone C (2003) Comparison of smectite-and illite-rich gouge frictional properties: application to the updip limit of the seismogenic zone along subduction megathrusts. Earth Planet Sci Lett 215(1-2):219-235

Salman R, Hill EM, Feng L, Lindsey EO, Veedu DM, Barbot S, Banerjee P, Hermawan I, Natawidjaja DH (2017) Piecemeal rupture of the Mentawai patch, Sumatra: The $2008 M_{w} 7.2$ North Pagai earthquake sequence. J Geophys Res Solid Earth 122:9404-9419

Sallarès V, Ranero CR (2019) Upper-plate rigidity determines depthvarying rupture behaviour of megathrust earthquakes. Nature 576(7785):96-101

Sapkota S, Bollinger L, Klinger Y, Tapponnier P, Gaudemer Y, Tiwari D (2013) Primary surface ruptures of the great Himalayan earthquakes in 1934 and 1255. Nat Geosci 6(1):71-76

Satake K (1994) Mechanism of the 1992 nicaragua tsunami earthquake. Geophys Res Lett 21 (23):2519-2522

Satake K, Tanioka Y (1999) Sources of tsunami and tsunamigenic earthquakes in subduction zones. Pure Appl Geophys 154(3-4):467-483

Satake K, Nishimura Y, Putra PS, Gusman AR, Sunendar H, Fujii Y, Tanioka Y, Latief H, Yulianto E (2013) Tsunami source of the 2010 Mentawai, Indonesia earthquake inferred from tsunami field survey and waveform modeling. Pure Appl Geophys 170(9-10):1567-1582

Sathiakumar S, Barbot S, Hubbard J (2020) Seismic cycles in fault-bend folds. J Res Geophys. https://doi.org/10.1029/2019JB018557

Savage J (2000) Viscoelastic-coupling model for the earthquake cycle driven from below. J Geophys Res 105(B11):25525-25532

Savage JC, Prescott WH (1978) Asthenosphere readjustement and the earthquake cycle. J Geophys Res 83(B7):3369-3376

Schellart WP, Rawlinson N (2013) Global correlations between maximum magnitudes of subduction zone interface thrust earthquakes and physical parameters of subduction zones. Phys Earth Planet Inter 225:41-67

Scholz CH (1998) Earthquakes and friction laws. Nature 391:37-42

Scholz CH, Molnar P, Johnson T (1972) Detailed studies of frictional sliding of granite and implications for earthquake mechanism. J Geophys Res 77(32):6392-6404

Schwartz SY, Rokosky JM (2007) Slow slip events and seismic tremor at circum-pacific subduction zones. Rev Geophys 45(RG3004). https:// doi.org/10.1029/2006RG000208

Scuderi MM, Collettini C, Viti C, Tinti E, Marone C (2017) Evolution of shear fabric in granular fault gouge from stable sliding to stick slip and implications for fault slip mode. Geology 45(8):731-734

Segall P (2010) Earthquake and volcano deformation. Princeton University Press, Princeton

Segall P, Bradley AM (2012) The role of thermal pressurization and dilatancy in controlling the rate of fault slip. J Appl Mech 79(3):031,013

Segall P, Rubin AM, Bradley AM, Rice JR (2010) Dilatant strengthening as a mechanism for slow slip events. J Geophys Res 115(B12305)

Shelly DR, Beroza GC, Ide S, Nakamula S (2006) Low-frequency earthquakes in Shikoku, Japan, and their relationship to episodic tremor and slip. Nature 442:188-191

Sherburn J, Horstemeyer M, Bammann D, Baumgardner J (2011) Application of the Bammann inelasticity internal state variable constitutive model to geological materials. Geophys J Int 184(3):1023-1036

Shibazaki B, Matsu'ura M (1992) Spontaneous processes for nucleation, dynamic propagation, and stop of earthquake rupture. Geophys Res Lett 19(12):1189-1192

Shibazaki B, Shimamoto T (2007) Modelling of short-interval silent slip events in deeper subduction interfaces considering the frictional properties at the unstable-stable transition regime. Geophys J Int 171(1):191-205

Shibazaki B, Matsuzawa T, Tsutsumi A (2011) 3D modeling of the cycle of a great Tohoku-Oki earthquake, considering frictional behavior at low to high slip velocities. Geophys Res Lett. https://doi.org/10.1029/2011GL049308

Shibazaki B, Obara K, Matsuzawa T, Hirose H (2012) Modeling of slow slip events along the deep subduction zone in the kii peninsula and tokai regions, Southwest Japan. J Geophys Res Solid Earth 117(B6)

Sieh K et al (2008) Earthquake supercycles inferred from sea-level changes recorded in the corals of West Sumatra. Science 322:1674-1678

Shiraishi K, Kazuya Moore GF, Yamada Y, Kinoshita M, Sanada Y, Kimura G (2019) Seismogenic Zone Structures Revealed by Improved 3-D Seismic Images in the Nankai Trough off. Kumano. G3 20(5):2252-2271

Sleep NH (1995) Ductile creep, compaction, and rate and state dependent friction within major fault zones. J Geophys Res 100(B7):13065-13080 
Sleep NH (2006) Real contacts and evolution laws for rate and state friction. Geochem Geophys Geosyst 7(8). https://doi.org/10.1029/2005GC0011 87

Sleep NH, Blanpied ML (1992) Creep, compaction and the weak rheology of major faults. Nature 359(6397):687

Sobolev SV, Muldashev IA (2017) Modeling seismic cycles of great megathrust earthquakes across the scales with focus at postseismic phase. Geochem Geophys Geosyst 18:4387-4408

Spiegelman M, McKenzie D (1987) Simple 2-D models for melt extraction at mid-ocean ridges and island arcs. Earth Planet Sci Lett 83(1-4):137-152

Stern RJ (2002) Subduction zones. Rev Geophys 40(4):1-3. https://doi, org/10.1029/2001RG000108

Sugioka H et al (2012) Tsunamigenic potential of the shallow subduction plate boundary inferred from slow seismic slip. Nat Geosci 5(6):414

Suito H (2017) Importance of rheological heterogeneity for interpreting viscoelastic relaxation caused by the 2011 Tohoku-Oki earthquake. Earth Planet Space 69(1):21. https://doi.org/10.1186/s40623-017-0639-x

Suito H, Freymueller JT (2009) A viscoelastic and afterslip postseismic deformation model for the 1964 Alaska earthquake. J Geophys Res 114(B11404):23

Sun T et al (2014) Prevalence of viscoelastic relaxation after the 2011 TohokuOki earthquake. Nature 514:84-87

Syracuse EM, Abers GA (2006) Global compilation of variations in slab depth beneath arc volcanoes and implications. Geochem Geophys Geosyst 7(5). https://doi.org/10.1029/2005GC001045

Szeliga W, Melbourne T, Santillan M, Miller M (2008) GPS constraints on 34 slow slip events within the Cascadia subduction zone, 1997-2005. J Geophys Res Solid Earth 113(B4). https://doi.org/10.1029/2007JB004948

Takagi R, Uchida N, Obara K (2019) Along-strike variation and migration of long-term slow slip events in the western nankai subduction zone, Japan. J Geophys Res 124(4):3853-3880

Takahashi N, Kodaira S, Park J-O, Diebold J (2003) Heterogeneous structure of western Nankai seismogenic zone deduced by multichannel reflection data and wide-angle seismic data. TECTON 364(3-4):167-190

Tang C-H, Hsu Y-J, Barbot S, Moore JDP, Chang W-L (2019) Lower-crustal rheology and thermal gradient in the Taiwan orogenic belt illuminated by the 1999 Chi-Chi earthquake. Nat Commun 5:eaav3287

Thatcher W (1984) The earthquake deformation cycle at the Nankai trough, Southwest Japan. J Geophys Res 89(B5):3087-3101

Thieme M, Demouchy S, Mainprice D, Barou F, Cordier P (2018) Stress evolution and associated microstructure during transient creep of olivine at 1000-1200 ${ }^{\circ} \mathrm{C}$. Physics Earth Planet Inter 278:34-46

Toh A, Obana K, Araki E (2018) Distribution of very low frequency earthquakes in the Nankai accretionary prism influenced by a subducting-ridge. EarthPlanet Sci Lett 482:342-356

Tomita F, Kido M, Ohta Y, linuma T, Hino R (2017) Along-trench variation in seafloor displacements after the 2011 tohoku earthquake. Sci Adv 3(7):e1700113

Tong X, Lavier LL (2018) Simulation of slip transients and earthquakes in finite thickness shear zones with a plastic formulation. Nat Commun 9(1):3893

Tsang LL, Hill EM, Barbot S, Qiu Q, Feng L, Hermawan I, Banerjee P, Natawidjaja $\mathrm{DH}$ (2016) Afterslip following the $2007 M_{w} 8.4$ bengkulu earthquake in sumatra loaded the $2010 M_{w} 7.8$ mentawai tsunami earthquake rupture zone. J Geophys Res 121(12):9034-9049. https://doi.org/10.1002/2016J B013432

Tse ST, Rice JR (1986) Crustal earthquake instability in relation to the depth variation of frictional slip properties. J Geophys Res 91(B9):9452-9472

Tsuji T, Ashi J, Ikeda Y (2014) Strike-slip motion of a mega-splay fault system in the Nankai oblique subduction zone. EPS 66(1):120

Tsuji T, Ashi J, Strasser M, Kimura G (2015) Identification of the static backstop and its influence on the evolution of the accretionary prism in the Nankai Trough. EPSL 431:15-25

Tsuji T, Minato S, Kamei R, Tsuru T, Kimura G (2017) 3D geometry of a plate boundary fault related to the 2016 Off-Mie earthquake in the Nankai subduction zone, Japan. EPSL 478:234-244

Tullis T, Weeks JD (1986) Constitutive behavior and stability of frictional sliding in granite. Pure Appl Geophys 124(3):383-394

Vaca S, Vallée M, Nocquet J-M, Battaglia J, Régnier M (2018) Recurrent slow slip events as a barrier to the northward rupture propagation of the 2016 Pedernales earthquake (central ecuador). Tectonophysics 724:80-92
Van der Wal D, Chopra P, Drury M, Gerald JF (1993) Relationships between dynamically recrystallized grain size and deformation conditions in experimentally deformed olivine rocks. Geophys Res Lett 20(14):1479-1482

van Keken PE, Hacker BR, Syracuse EM, Abers GA (2011) Subduction factory: 4. Depth-dependent flux of h2o from subducting slabs worldwide. J Geophys Res 116(B1). https://doi.org/10.1029/2010JB007922

Van Rijsingen E, Lallemand S, Peyret M, Arcay D, Heuret A, Funiciello F, Corbi F (2018) How subduction interface roughness influences the occurrence of large interplate earthquakes. Geochem Geophys Geosyst 19(8):2342-2370

Veedu DM, Barbot S (2016) The Parkfield tremors reveal slow and fast ruptures on the same asperity. Nature 532(7599):361-365. https://doi. org/10.1038/nature17190

Viesca RC (2016a) Stable and unstable development of an interfacial sliding instability. Phys Rev E 93(6):060202

Viesca RC (2016b) Self-similar slip instability on interfaces with rate-and statedependent friction. Proc R Soc A 472(2192):20160,254

Wada I, Wang K (2009) Common depth of slab-mantle decoupling: Reconciling diversity and uniformity of subduction zones. Geochem Geophys Geosyst 10(10). https://doi.org/10.1029/2009GC002570

Wallace LM, Beavan J (2006) A large slow slip event on the Central Hikurangi subduction interface beneath the Manawatu region, north island, New Zealand. Geophys Res Lett 33(11). https://doi.org/10.1029/2006GL0260 09

Wallace LM et al (2016) Near-field observations of an offshore $M_{w} 6.0$ earthquake from an integrated seafloor and subseafloor monitoring network at the Nankai trough, Southwest Japan. J Geophys Res 121(11):8338-8351

Wallace LM, Kaneko Y, Hreinsdóttir S, Hamling I, Peng Z, Bartlow N, D'Anastasio E, Fry B (2017) Large-scale dynamic triggering of shallow slow slip enhanced by overlying sedimentary wedge. Nat Geosci 10:765-770

Wang K (2007) Elastic and viscoelastic models of crustal deformation in subduction earthquake cycles, The seismogenic zone of subduction thrust faults, pp 540-575

Wang K, Hu Y, He J (2012) Deformation cycles of subduction earthquakes in a viscoelastic earth. Nature 484(7394):327

Wei M, Liu Y, Kaneko Y, McGuire JJ, Bilham R (2015) Dynamic triggering of creep events in the Salton Trough, southern California by regional $\mathrm{m} \geq$ 5.4 earthquakes constrained by geodetic observations and numerical simulations. Earth Planet Sci Lett 427:1-10

Wei M, Kaneko Y, Shi P, Liu Y (2018) Numerical modeling of dynamically triggered shallow slow slip events in New Zealand by the $2016 M_{w} 7.8$ Kaikoura earthquake. Geophys Res Lett 45(10):4764-4772

Weiss JR et al (2019) Anatomy of the postseismic deformation following the $2010 M_{w}=8.8$ Maule earthquake in Chile. Sci Adv. https://doi. org/10.1126/sciadv.aax6720

Wu Y, Chen X (2014) The scale-dependent slip pattern for a uniform fault model obeying the rate-and state-dependent friction law. J Geophys Res 119(6):4890-4906

Wu C, Chen Q, Basack S, Xu R, Shi Z (2016) Biaxial creep test study on the influence of structural anisotropy on rheological behavior of hard rock. J Mater Civil Eng 28(10):04016,104

Yamanaka Y, Kikuchi M (2004) Asperity map along the subduction zone in northeastern Japan inferred from regional seismic data. J Geophys Res 109(B07307):14. https://doi.org/10.1029/2003JB002683

Yamashita F, Fukuyama E, Mizoguchi K (2014) Probing the slip-weakening mechanism of earthquakes with electrical conductivity: rapid transition from asperity contact to gouge comminution. Geophys Res Lett $41(2): 341-347$

Yamashita Y et al (2015) Migrating tremor off southern Kyushu as evidence for slow slip of a shallow subduction interface. Science 348(6235):676-679

Yarai H, Ozawa S (2013) Quasi-periodic slow slip events in the afterslip area of the 1996 Hyuga-Nada earthquakes, Japan. J Geophys Res 118(5):2512-2527

Ye L, Lay T, Kanamori H, Rivera L (2016) Rupture characteristics of major and great ( $m w \geq 7.0$ ) megathrust earthquakes from 1990 to 2015: 1. Source parameter scaling relationships. J Geophys Res 121(2):826-844

Ye L, Kanamori H, Lay T (2018) Global variations of large megathrust earthquake rupture characteristics. Sci Adv 4(3):eaao4915 
Yu H, Liu Y, Yang H, Ning J (2018) Modeling earthquake sequences along the manila subduction zone: effects of three-dimensional fault geometry. Tectonophysics 733:73-84

Yue H, Lay T, Rivera L, An C, Vigny C, Tong X, Báez Soto JC (2014) Localized fault slip to the trench in the 2010 Maule, $C$ ile $M_{w}=8.8$ earthquake from joint inversion of high-rate GPS, teleseismic body waves, INSAR, campaign GPS, and tsunami observations. J Geophys Res 119(10):7786-7804

Ziv A, Cochard A (2006) Quasi-dynamic modeling of seismicity on a fault with depth-variable rate- and state-dependent friction. J Geophys Res 111(B08310):11

\section{Publisher's Note}

Springer Nature remains neutral with regard to jurisdictional claims in published maps and institutional affiliations.

\section{Submit your manuscript to a SpringerOpen ${ }^{\circ}$ journal and benefit from:}

- Convenient online submission

- Rigorous peer review

- Open access: articles freely available online

- High visibility within the field

- Retaining the copyright to your article

Submit your next manuscript at $\boldsymbol{\nabla}$ springeropen.com 